\title{
ORDEN, JERARQUÍA E IGUALDAD EN EL PENSAMIENTO DE NICOLÁS GÓMEZ DÁVILA
}

\author{
Francisco Cuena Boy \\ Catedrático de Derecho Romano \\ Facultad de Derecho \\ de la Universidad de Cantabria \\ francisco.cuena@unican.es
}

\begin{abstract}
RESUMEN
Ensayo de compilación de textos gomezdavilianos con miras a la exposición ordenada del pensamiento del filósofo colombiano acerca de los tres conceptos que componen el título, aclarando sus conexiones esenciales y añadiendo interpretaciones propias alli donde al autor le ha parecido posible introducirlas.

Palabras clave: Nicolás Gómez Dávila, orden, jerarquía, igualdad, feudalismo, aristocracia.

\section{ABSTRACT}

Compilation of Gomezdavilian texts for the orderly exposition of the Colombian philosopher's thougt about the three concepts that compose the title, clarifying their essential connections and adding author's interpretations where it seemed possible to introduce them.
\end{abstract}

Keywords: Nicolás Gomez Dávila, order, hierarchy, equality, feudalism, aristocracy.

\section{ZUSAMMENFASSUNG}

Kompilation's essay von «gomezdavilianischen» Texte für die geordnete Darstellung des Denken des kolumbianischen Philosophen in bezug auf den drei Konzepte, die den Titel bilden, um ibre wesentlichen Zusammenbänge zu klären und die Interpretationen des Autors hinzufügen dort, wo es möglich sei.

Schlüsselwörter: Nicolás Gómez Dávila, Ordnung, Hierarchie, Gleichheit, Feudalismus, Aristokratie.

SUMARIO: I. EXORDIO.-II. ORDEN.-III. JERARQUÍA.-IV. EL MODELO GOMEZDAVILIANO DE SOCIEDAD JERÁRQUICA (O JERARQUIZADA).-1. Feudalismo.-2. Aristocracia.-V. IGUALDAD.—1. Conclusión mínima sobre la igualdad. 


\section{EXORDIO}

No está a mi alcance escribir como Nicolás Gómez Dávila. Sí creo haberlo leído con afán crítico semejante al que tuvo que utilizar él con los autores de su biblioteca para destilar luego sus Notas, sus Textos y, sobre todo, sus Escolios $^{1}$. En esta ocasión me ocupo de un tema principal del pensamiento gomezdaviliano en el que me fijé ya desde mi primera lectura de los Escolios. Lo hago con el mayor de los respetos, pero también con la libertad que me imponen todo tipo de limitaciones que afectan a mí persona. $\mathrm{Y}$ con esto brindo al lector una de esas paradojas que tanto gustaban a nuestro autor. Quiero subrayar que no he pretendido agotar el asunto tratado; lejos de ello, me he limitado a reunir cierta cantidad de lugares del colombiano sobre orden, jerarquía e igualdad y a presentarlos en forma más o menos arreglada, intercalando donde me ha parecido oportuno, o simplemente posible, algún comentario o interpretación de mi propia cosecha. Si alguien me dijera que en la reunión y combinación de los materiales se esconden varias o muchas interpretaciones implícitas no dejaría yo de darle la razón².

\section{ORDEN}

De los tres conceptos que figuran en el título, el único que se presenta a primera vista con carácter sustantivo es el de orden, ya que que los otros dos no son, siempre a primera vista, más que criterios de una eventual ordenación. El Diccionario de la Real Academia Española (DRAE) recoge veintiuna acepciones de la palabra «orden» (del latín ordo,

${ }^{1}$ Las citas de Notas se refieren a la edición de Villegas, Bogotá, 2003, y las de Textos a la de Atalanta, Vilaür (Gerona), 2010, en cuyas últimas páginas (149-159) se recoge «El reaccionario auténtico», publicado originalmente en la Revista de la Universidad de Antioquia, núm. 240 (1995). Los Escolios se citarán por la edición completa de Atalanta, Escolios a un texto implícito, Vilaür (Gerona), 2009, indicando de forma abreviada el título del volumen original (y el número cuando proceda) y la página o páginas de esta edición.

${ }_{2}^{2}$ La posibilidad de multiplicar las lecturas de los Escolios «a través del esparcir de las conexiones» ya fue advertida por M. Ayuso, «Conservación, tradición y reacción. Una reflexión en torno de la obra de Nicolás Gómez Dávila», en B. J. OBiDZí́ska y K. URBANEK (eds.), Między sceptycyzmem a wiara. Nicolás Gómez Dávila i jego dzieło [Entre el escepticismo y la fe. Nicolás Gómez Dávila y su obra], Warszawa, Furta Sacra, 2008, p. 126; por parecido sendero discurren las consideraciones de S. ZuCAL, «Tradizione e significato dell'aforisma: Ferdinand Ebner e Gómez Dávila alla scuola di Nietzsche», en F. MEROI y S. Zucal (eds.), Nicolás Gómez Dávila e la crisi dell'Occidente, Pisa, ETS, 2014, p. 156. 
-inis). Varias de ellas indican ideas estrechamente afines. Partiendo de la primera — «colocación de las cosas en el lugar que les corresponde»-, se comprenden mejor la segunda — «concierto, buena disposición de las cosas entre sí»-, la séptima — «relación o respecto de una cosa a otra»-, la novena — «cierta disposición y proporción de los cuerpos principales que componen un edificio»-o la décima — «cada uno de los grupos taxonómicos en que se dividen las clases y que se subdividen en familias»- Relación o respecto, concierto o buena disposición, disposición y proporción, división en grupos, todo ello bajo el presupuesto o como resultado de la colocación de cada objeto en el lugar que le corresponde. Otras acepciones transmiten la idea de que la colocación en el lugar adecuado presupone la identificación de categorías o niveles distintos o que, en todo caso, desemboca en ella; así la sexta — «nivel o categoría que se atribuye a alguien o algo»—, la octava — «en determinadas épocas, grupo o categoría social»—, la decimoquinta — «cierta categoría o coro de espíritus angélicos»— y la vigésima — «cada uno de los grados del sacramento del orden, que se van recibiendo sucesivamente y constituyen ministros de la Iglesia»-. Por último, según la tercera acepción, orden es «regla o modo que se observa para hacer las cosas», y según la quinta, «ámbito de materias o actividades en el que se enmarca alguien o algo».

Conforme a su concepción medieval, el orden no es impensable respecto de un único objeto ${ }^{3}$. En cambio, cualquiera de las acepciones reseñadas sobrentiende la existencia de una pluralidad de «cosas»o elementos -individuales y discretos- cuyo conjunto constituye el universo ordenado o susceptible de recibir un orden; éste nacerá de la implementación de un criterio determinado que a su vez vendrá dado por el fin o fines que para el orden mismo se contemplan. Como se podrá comprobar, ésta parece ser también la noción de orden en torno a la que giran los comentarios gomezdavilianos. En ellos, lo que acabamos de llamar «universo» asume expresiones muy heterogéneas: los cuerpos celestes $^{4}$, los héroes y los dioses ${ }^{5}$, el mundo ${ }^{6}$, la sociedad ${ }^{7}$, las $\operatorname{artes}^{8}$, las

3 Señala Landsberg (citado por J. Ferrater Mora, Diccionario de filosofía, vol. 3, Madrid, Alianza Editorial, 1984, p. 2445, s. v. Orden) que en el concepto medieval de orden «una sola cosa aislada puede estar bien "ordenada”, ser justa, siempre que tenga con su idea, preexistente en Dios, la relación de adecuación».

${ }^{4}$ Notas, p. 92.

${ }^{5}$ Escolios, I, p. 247.

${ }^{6}$ Escolios, I, p. 389, y II, p. 651.

7 Notas, pp. 76, 87 y 92, y Escolios, II, p. 763.

${ }^{8}$ Escolios, II, p. 763. 
verdades $^{9}$, el individuo ${ }^{10}$ e incluso, con vocablo incoloro pero que todo lo abarca, las $\operatorname{cosas}^{11}$. Es importante subrayar que se trata en todos los casos de entidades múltiples o compuestas con independencia del número gramatical de la palabra que vez por vez las designa.

Como preámbulo al examen de los textos sobre la idea de orden parece inexcusable comenzar con un escolio, no de los más cortos, pero a cambio muy general, que culpa a la escolástica de haber aplicado la noción platónica de orden - el orden inteligible de las ideas, inmutable, absoluto, necesario, independiente de la experiencia sensible- al «mundo sublunar del aristotelismo», cuando lo cierto es que éste se explicaría mejor por la noción antagónica de desorden. Sin entrar en profundidades que no son de este lugar, el corazón del reproche consiste en haber pretendido la escolástica que el orden reside en las cosas y en su disposición según el espacio-tiempo, siendo así que al pensamiento cristiano debería haberle bastado el dogma del pecado original para entender y aceptar que el orden no está en las cosas, sino tras ellas: «Ordo es lo que trasparenta el mundo sin hacer parte de él, como las normas, las estructuras, los valores» ${ }^{12}$. Inevitablemente, el significado de este pasaje compone un telón de fondo sobre el que se deberían leer los demás comentarios del colombiano. En estas páginas no vamos a intentar la verificación concreta de su influencia, pero sí conviene indicar al menos un tema en el que se deja sentir con toda su fuerza: la posición antiiusnaturalista de Gómez Dávila ${ }^{13}$.

Entrando en materia cabe preguntar, en primer lugar, cómo es intrínsecamente el orden de los universos que hemos enumerado y también, en paralelo, si el ser intrínseco del orden no cambia cualquiera que sea su

9 Notas, p. 76; Nuevos escolios, I, p. 931, y Sucesivos escolios, p. 1259.

${ }^{10}$ Nuevos escolios, I, p. 986.

${ }_{11}$ Nuevos escolios, I, p. 1051.

12 Escolios, II, p. 481: «El pensamiento moderno surge en los escombros de la noción escolástica de ordo.// La escolástica misma causó el desastre, aplicando una noción originaria del cielo platónico al mundo sublunar del aristotelismo. La noción fracasa en un universo que la noción antagónica de desorden explica mejor.// Bastaba, sin embargo, el dogma del pecado original para que el pensamiento cristiano sólo buscara el orden tras las cosas, así como buscamos las estructuras lógicas detrás de la materia empírica de la psicología.// Ordo es lo que trasparenta el mundo sin hacer parte de él, como las normas, las estructuras, los valores».

${ }_{13}$ Es suficiente el siguiente escolio: «Ni en la naturaleza del mundo, ni en la naturaleza del hombre, existen rastros de normas.// Las normas resultan de intromisiones de la voluntad.// De una voluntad sometida a la percepción de un valor» (Sucesivos escolios, p. 1270). Sobre la cuestión en su conjunto vid. F. CuENA BOy, «Nicolás Gómez Dávila, la historia, el derecho», RGDR, núm. 16 (2011), pp. 12 y ss. 
universo. A juzgar por las respuestas de Gómez Dávila, el contenido de esta pregunta es más complejo de lo que pudiera parecer; por ejemplo, según un texto de Notas $^{14}$, orden natural no es acaso lo mismo que orden inviolable, ya que el autor discurre acerca de un orden de la sociedad humana susceptible de ser violado pese a atribuirle, siquiera como hipótesis, la calidad de «esencial y natural»; a su vez, no obstante, orden violable no equivale a orden superfluo o innecesario, pero tampoco la necesidad del orden — seguimos hablando de la sociedad — se iguala con la esencialidad del mismo, sino que se sitúa en un plano distinto. Un orden inviolable es «el conjunto de leyes de la mecánica celeste», que probablemente es también un orden natural y, en cuanto inviolable, un orden necesario: natural, inviolable y necesario. En la hipótesis de que existiera, «un orden esencial y natural de la sociedad humana» sería, en cambio, perfectamente violable, pero no por ello prescindible en el sentido de que su violación carezca de graves consecuencias: orden esencial y natural, violable y necesario. La clave de la diferencia parece residir en la ineluctabilidad de cada orden en su contextura concreta y en la forma distinta en que se predica su calidad de necesario, lo cual, a su vez, parece guardar relación estrecha con la diferencia de universos. El orden celeste (o el orden de la respiración, si fuera lícito hablar de esta manera) es natural porque no es artificial o producido por el hombre, es inviolable porque quebrantarlo no está al alcance de los elementos que en él se ordenan, y es necesario porque su destrucción comportaría la de los propios elementos ordenados. La naturalidad de un orden concreto de la sociedad humana no es más que una hipótesis; cualquier orden de la sociedad humana puede ser violado, pero toda sociedad humana necesita el orden (esto es, algún orden) que es «condición de un estado social determinado» ${ }^{15}$.

${ }^{14}$ Notas, p. 92: «En caso de que exista un "orden esencial y natural de la sociedad humana", no se trata de un orden inviolable como el conjunto de las leyes de la mecánica celeste.// Por lo tanto, una institución social como la familia no comporta una necesidad semejante a la de la respiración, por ejemplo.// En verdad ese orden no puede ser sino la condición de un estado social determinado; violarlo, sin embargo, puede implicar la destrucción de todo lo que, en él, coexiste. Así, ese orden puede no ser esencial al hombre como organismo, para sobrevivir, pero sí a todo lo que hay de propiamente humano en el hombre». Entendiendo que «orden» está aquí por «derecho», J. M. SERRANo Ruiz-CaldERÓN, Democracia y nibilismo. Vida y obra de Nicolás Gómez Dávila, Pamplona, Eunsa, 2015, pp. 84 y ss., relaciona este texto con el antiiusnaturalismo de Gómez Dávila.

${ }^{15}$ Cfr. H. Barth, Die Idee der Ordnung. Beiträge zu einer Politischen Philosophie, Zürich-Stuttgart, 1958, p. 215: «Ordnung ist niemals etwas, das sich mit einer Art naturhafter Notwendigkeit, gegen den Willen des Menschen, durchsetzt [...] Wo Ordnung herrschen soll, da muß die Ordnung selbst oder doch der Sinn oder Zweck, der sich in der Ordnung ausdrückt, zum Beweggrund des menschlichen Handelns erhoben werden». 
En la cuestión del orden social, el hombre no se juega su supervivencia como organismo, pero sí todo aquello que, separándolo de los demás organismos, le hace propiamente humano.

Un escolio que afirma que «el orden es engaño.// Pero el desorden no es solución ${ }^{16}$ se nos antoja síntesis parcial de lo anterior. Aunque nos hace dudar otro según el cual «nada parece más desordenado, en la sociedad o en las artes, que el orden auténtico» ${ }^{17}$. ¿Hay pues un orden auténtico en la sociedad o en las artes?, ¿qué significa auténtico en comparación con natural y en comparación con necesario?, ¿cómo se determina la autenticidad de un orden? El adjetivo auténtico vuelve a figurar en otro pasaje que insinúa la existencia de alguna relación entre el orden y la autenticidad: «Al individuo auténtico — dice— no es posible sumarlo, sólo es posible ordenarlo» ${ }^{18}$. Ahora bien, en cuanto predicado del individuo, la autenticidad consiste en la consecuencia consigo mismo ${ }^{19}$, de donde se puede inferir que orden auténtico es el que se corresponde con la autenticidad de sus elementos, aquel que, acogiéndolos, permite que se muestren tal y como son. Sea o no acertada esta deducción, y suponiendo que la autenticidad admite grados, aún se podría preguntar si hay órdenes inauténticos o meramente puntos de mayor cercanía o distancia respecto al orden auténtico, único por definición; en el extremo, la negación total del mismo.

El texto de Notas del que ha partido el análisis enunciaba la hipótesis de un «orden esencial y natural de la sociedad humana» sin autorizarla ni desmentirla, sino con el propósito de evidenciar las limitaciones de un orden con esos atributos por comparación con el de la mecánica celeste. Aquella hipótesis se rechaza explícitamente en otro pasaje de la misma obra donde se afirma que los órdenes posibles de la sociedad son tantos como las sociedades posibles ${ }^{20}$. Aun así, no parece dudoso que para cada sociedad posible deba existir un orden del tipo que fuere, que será el auténtico de ella; un orden quebrantable, desde luego, pero necesario

${ }^{16}$ Escolios, II, p. 711.

${ }^{17}$ Escolios, II, p. 763.

${ }_{18}$ Nuevos escolios, I, p. 986. A lo largo de la exposición se podrá ir coligiendo el significado de la diferencia que apunta este comentario entre suma y orden u ordenación de individuos.

${ }^{19}$ Segunda acepción de auténtico en el Diccionario de la Real Academia Española.

${ }^{20}$ Notas, p. 87: «Buscar la solución del problema social, es decir, aspirar a un equilibrio perfecto y definitivo, es un anhelo absurdo porque presupone que existe un orden esencial de la sociedad, cuando en realidad hay tantos órdenes posibles como hay sociedades posibles y casi tantos como hay individuos posibles». 
para su duración. «El orden — dice nuestro autor— es el más frágil de los hechos sociales» ${ }^{21}$.

Dejando al margen el conjunto de leyes de la mecánica celeste —único ejemplo de orden inviolable que nos ha salido al paso_-, Gómez Dávila parece pensar poco más o menos que el orden es un constructo humano; en consecuencia, algo artificial. Ésta es, por lo menos en parte, la enseñanza de un escolio en el que afirma que «el mundo no sufre más orden sistemático que el orden alfabético del diccionario» ${ }^{22}$; no tanto la de otro que admite la existencia de islotes de orden en el universo al mismo tiempo que tacha de artefacto ideológico el supuesto orden del mundo ${ }^{23}$. Pero si el orden del mundo es aquí imaginario, mero artefacto ideológico, ¿cómo es que otro escolio contrapone el «orden del hombre» y el «orden del mundo», elogiando la rebelión contra el primero pero advirtiendo del peligro de insubordinación contra el segundo que se podría esconder detrás de ella? ${ }^{24} \mathrm{Si}$ el «orden del hombre» es el de la sociedad humana, como parece lógico suponer ${ }^{25}$, ya se ha visto que ese orden es artificial, frágil y quebrantable, por más que también necesario; la nobleza de la actitud que lo desafía se comprende sin especial dificultad. Pero que pueda ser disfraz de un intento de subvertir el «orden del mundo» choca con lo afirmado en los escolios citados con anterioridad. Ciertamente, el obstáculo que representa el primero de ellos se podría superar postulando la existencia de un «orden del mundo» de tipo no sistemático ${ }^{26}$, ya que en ese escolio se dice que el único «orden sistemático» que soporta el mundo es el orden alfabético del diccionario. Pero esto no es suficiente para superar también la afirmación explícita del segundo escolio: «el supuesto orden del mundo es artefacto ideológico». No es fácil salir de estas aporías gomezdavilianas ni siquiera con ayuda de aquel canon metodológico del autor según el cual «no es a resolver contradicciones, sino a ordenarlas, a

${ }^{21}$ Nuevos escolios, II, p. 1097. Con implicaciones jurídicas, cfr. Escolios, II, p. 740: «Orden es lo que resulta espontáneamente de una norma.// No lo que unas reglas imponen».

22 Escolios, I, p. 389.

${ }^{23}$ Escolios, II, p. 651: «En el universo hay islotes de orden.// Pero el supuesto orden del mundo es artefacto ideológico» (es de suponer que universo y mundo son aquí sinónimos). Por otro lado, los «islotes de orden» aludidos, ¿son manifestaciones espontáneas de orden?

${ }^{24}$ Escolios, I, p. 275: «Toda rebelión contra el orden del hombre es noble, mientras no disfrace una rebeldía contra el orden del mundo».

${ }^{25}$ Sin perjuicio de que otros comentarios permitan inferir la existencia de un orden propio de cada individuo vid. Escolios, I, p. 176: «Todo nos parece caos, menos nuestro propio desorden», y Nuevos Escolios, I, p. 919: «El estilo es orden a que el hombre somete el caos».

${ }^{26}$ Cfr. Escolios, II, p. 578: «El universo no es sistema, es decir, coherencia lógica.// Sino estructura jerárquica de paradojas», y Notas, p. 289: «Hay que jerarquizar al universo, provisionalmente». 
lo que podemos pretender ${ }^{27}$; ningún criterio de ordenación sirve, en efecto, cuando de uno de los elementos a ordenar se afirma sucesivamente la existencia y la inexistencia.

En cuanto a la verdad y las verdades, dos escolios instruyen al lector de que también para ellas el orden es necesario ${ }^{28}$, aunque sobre otras características intrínsecas de aquel que pudiera convenirles —esencialidad, inviolabilidad, autenticidad - guardan absoluto silencio. Quizá son más elocuentes otros dos textos, respectivamente de Notas y de los Escolios, que dejan entrever una de las piedras angulares del pensamiento gomezdaviliano, la jerarquía, cuya importancia para el asunto de este trabajo sería inútil ponderar en este momento. El primero menciona el «orden diverso» y el «valor distinto» de las diferentes verdades ${ }^{29}$; el segundo habla directamente de «la colocación jerárquica de las verdades» ${ }^{30}$. Si de ambos cabe deducir el carácter jerárquico de la «límpida estructura» en que se ordenan las verdades, entonces habrá que concluir, asimismo, que el orden auténtico de ellas es de aquel mismo carácter. Por lo demás, el último escolio citado indica la posibilidad de confusiones de la conciencia individual en lo que respecta a la colocación de las verdades, lo que sugiere la idea de que el orden (o el orden asequible) de éstas es, asimismo, artificial.

En realidad, para Gómez Dávila el orden se identifica con la jerarquía hasta el punto de poder afirmar que «la nivelación es el substituto bárbaro del orden» ${ }^{31}$. Por otra parte, el orden — por supuesto jerárquico— es la

${ }^{27}$ Nuevos escolios, I, p. 934.

28 Nuevos escolios, I, p. 931: «La verdad total no será empacho de un proceso dialéctico que engulle todas las verdades parciales, sino límpida estructura en que se ordenan»; Sucesivos escolios, p. 1259: «Las verdades no se contradicen sino cuando se desordenan», y Escolios, II, p. 638: «Las proposiciones, fuera del campo estrictamente científico, no se contradicen, sino se subordinan.// El error es una verdad de ínfimo rango».

${ }_{29}$ Notas, p. 76: «Toda proposición con sentido es una verdad: verdades, sin embargo, de orden diverso y de valor distinto». Para un breve comentario vid. G. ZuppA, «Quando l'Occidente muore. Nicolás Gómez Dávila; rilevanza e attualità del suo pensiero», en F. Meroi y S. Zucal (eds.), Nicolás Gómez Dávila e la crisi dell'Occidente, Pisa, ETS, 2014, p. 23. Implícita, pero aun así indudable, es la alusión a la jerarquía en Escolios, I, p. 247: «Un pensamiento católico no descansa, mientras no ordene el coro de los héroes y los dioses en torno a Cristo». Cfr. también los escolios citados en la nota anterior.

${ }^{30}$ Nuevos escolios, II, p. 1123: «La colocación jerárquica de las verdades no nos exime de los conflictos trágicos, pero nos salva de atribuir las confusiones de la conciencia individual a incoherencia del orden objetivo de las cosas». Cfr. también Escolios, II, p. 693: «Para comprender es preciso jerarquizar las verdades». Sobre el significado de «verdad» y «verdades» en las referencias gomezdavilianas vid. un apunte en F. MEROI, «Reazione e scetticismo: Gómez Dávila e Cioran», en F. Meror y S. ZuCAL (eds.), Nicolás Gómez Dávila e la crisi dell'Occidente, Pisa, ETS, 2014, p. 185.

31 Escolios, I, p. 152. 
clave de la justicia ${ }^{32}$, pero, en cambio, la libertad es fruto de compromisos limitados entre el orden y el desorden ${ }^{33}$; en esto último es básica la dosificación, ya que de ella depende el equilibrio capaz de evitar tanto la parálisis como la convulsión ${ }^{34}$. Antes que tantos y tantos lugares de los Escolios que dan nombre y perfil propio a dicho equilibrio, incluido el que se acaba de citar, un pasaje de Notas explica que «en una sociedad ordenada para la libertad habría una jerarquía de poderes, de privilegios y de libertades, para que se creara una tal diversidad de situaciones que ninguna uniformidad de deseos pudiera, jamás, realizarse» ${ }^{35}$. Más allá del sentido explícito de estas palabras, de ellas resulta también que la libertad es o puede ser uno de los fines del orden social —es de suponer que igualmente lo puede ser la justicia-, y que las contradicciones y las incoherencias sociales, o bien son ordenables ${ }^{36}$, o bien representan el ingrediente de desorden que, junto con el orden (o más bien dentro de él, como podremos ver más adelante), garantiza la libertad.

Por último, al tiempo que certifican la artificialidad del orden en general, dado que para su fábrica se necesita una determinada capacidad consistente en saber preferir, varios escolios señalan su incompatibilidad con el relativismo y la exclusión ${ }^{37}$.

32 Escolios, I, p. 255: «Entre injusticia y desorden no es posible optar.// Son sinónimos».

33 Sucesivos escolios, p. 1320: «La libertad no es fruto del orden sólo, es fruto de concesiones mutuas entre el orden y el desorden». Vid. una formulación anterior y menos precisa en Escolios, II, p. 705: «La libertad es el producto del ajuste imperfecto entre las piezas de la maquinaria social». Cfr. Nuevos escolios, II, p. 1179: «Donde imprudentemente toleremos aglomeraciones, orden y tiranía acaban desgraciadamente coincidiendo»; como imagen de la multiplicidad desordenada, la aglomeración es amontonamiento de elementos (tratados como si fueran) iguales.

${ }^{34}$ Escolios, II, p. 841: «El orden paraliza. El desorden convulsiona». La segunda parte de este escolio explica cómo pueda ser la combinación deseable de orden y desorden: «Inscribir un desorden instituido dentro de un orden englobante fue el milagro del feudalismo». Sobre esto vid. infra el apartado IV sobre el modelo gomezdaviliano de sociedad jerárquica (o jerarquizada).

${ }^{35}$ Notas, p. 70; en la continuación del pasaje se hace referencia a la beneficiosa presencia en el cuerpo político de «apetitos de libertad incoherentes y contradictorios» que se vigilan mutuamente y «de cuya armonía y de cuyo equilibrio puede nacer únicamente la garantía de una libertad real y soberana».

${ }^{36}$ Recuérdese lo dicho en Nuevos escolios, I, p. 934: «No es a resolver contradicciones, sino a ordenarlas, a lo que podemos pretender». Cfr. Sucesivos escolios, p. 1283: «El mundo se llena de contradicciones cuando olvidamos que las cosas tienen rango».

37 Escolios, I, p. 165: «No rechazar, sino preferir»; Nuevos escolios, I, p. 1051: «El relativismo es la solución del que es incapaz de poner las cosas en orden», y Nuevos escolios, II, p. 1229: «El que sabe preferir no excluye.// Ordena». 


\section{JERARQUÍA}

Pasamos a ver ahora qué nos deparan los muy numerosos textos gomezdavilianos acerca de la jerarquía y el orden jerárquico. Algo a este respecto ya lo hemos adelantado al analizar la noción de orden, lo que no es casual porque, aunque al principio señalábamos que la jerarquía sólo es uno de los criterios de orden posibles, después hemos comprobado que Nicolás Gómez Dávila identifica prácticamente ambos conceptos, lo que hace de forma especialmente patente cuando habla de la sociedad.

Queda ahora más claro qué es lo que quería decir cuando escribió en Notas que todo lo que hay de propiamente humano en el hombre depende del orden ${ }^{38}$ : el que él tenía en mente es claramente el orden jerárquico, y su convicción en este sentido se refrenda en una serie de escolios que la perfilan mejor todavía. El más extremado, fijándose aún en el individuo no como mero organismo, pero tampoco todavía en la sociedad, afirma que «el hombre emerge de la bestia al jerarquizar sus instintos» ${ }^{39}$. Otro señala que «tan sólo una ordenación jerárquica salva al individuo de petrificarse en mónada hermética o de licuarse en fango colectivo» ${ }^{40}$. En línea con él, el tercero y más expresivo culpa a la abolición de la sociedad jerárquica de la alienación (Entfremdung) del individuo y completa el círculo con el aserto de que «la jerarquía salva, en la sociedad civilizada, el cara a cara de la comunidad primitiva» ${ }^{41}$. Pues bien, puesto que la jerarquía «salva» el peligro del «cara a cara de la comunidad primitiva», parece evidente que no lo elimina, sino sólo lo contiene, de modo que podría resurgir con la supresión de aquélla; de ahí el calificativo de «substituto bárbaro del orden» que recibe de Gómez Dávila la nivelación ${ }^{42}$.

\footnotetext{
38 Vid. supra, nota 14.

39 Nuevos escolios, I, p. 961.

40 Nuevos escolios, I, p. 955. «Mónada hermética» y «fango colectivo» se corresponden respectivamente con la «soledad individual» y la «asfixia colectiva» de otro escolio que pondera la sociedad del siglo XVIII (Escolios, I, p. 284).

${ }^{41}$ Nuevos escolios, I, p. 981: «La abolición de la sociedad jerárquica motivó el Entfremdung.// El individuo, en efecto, se aliena en toda actividad social cuyo fin no sea otro individuo concreto.// La jerarquía salva, en la sociedad civilizada, el cara a cara de la comunidad primitiva». De este comentario resulta de alguna forma la ecuación jerarquía $=$ sociedad civilizada.

${ }^{42}$ Escolios, I, p. 152. La barbarie, según Textos, p. 104, es «regresión imprevista; súbito retroceso sobre una existencia limitada a las urgencias biológicas»; más que humano, el bárbaro es mero organismo.
} 
Algún fogonazo disperso por los Escolios en forma de declaración apodíctica reclama especial atención y sirve a la vez para ir centrando mejor el tema. Ante todo aquel comentario que declara que «el hombre tiene un apetito ingénito de jerarquía, que las falsas jerarquías convierten en asco» ${ }^{43}$. La jerarquía, así pues, vista como afán que nace con el hombre mismo, y las jerarquías «falsas» como causa de rebelión contra la jerarquía a secas. Una frase como «la vida es taller de jerarquías.// Sólo la muerte es demócrata» ${ }^{44}$ registra, sí, sendas evidencias al alcance de cualquiera, pero el uso de la palabra taller parece teñir las jerarquías vitales con el matiz propio de lo artificial ${ }^{45}$. La amistad es el único ámbito de la vida que hace excepción a la regla anterior: «Tan sólo entre amigos no hay rangos» ${ }^{46}$, y de nuevo se trata de algo sacado de la más común experiencia. Por el contrario, lo social es discurso que tiene su sintaxis particular en la jerarquía ${ }^{47}$, y si esto es así, la metáfora podría continuar afirmando que el discurso social que desprecia la jerarquía o ignora su compostura acaba siendo incoherente o por lo menos insubstancial ${ }^{48}$. Ahora bien, ¿qué significa aquel otro aserto según el cual «jerarquía es el principio que salva las contradicciones»? ${ }^{49}$ Con formulación más o menos parecida, esta idea la hemos encontrado antes en otros lugares ${ }^{50}$. En el actual se dice que la jerarquía es un principio, criterio

${ }^{43}$ Escolios, I, p. 397.

${ }^{44}$ Escolios, I, p. 438. Se trata de un tópico universal; cfr., p. ej., Horat., Carm., 1.4.13-14: «Pallida Mors aequo pulsat pede pauperum tabernas regumque turris».

${ }^{45}$ No hay contradicción con Escolios, II, p. 774: «Las jerarquías son celestes.// En el infierno todos son iguales». Si la hubiera, más que intentar deshacerla deberíamos proponer la ordenación de sus términos, ante todo advirtiendo que cada aserto tiene una intención diferente y que el citado en esta nota responde al propósito de encarecer en sí misma la noción de jerarquía, y después subrayando que uno contempla la vida terrenal del hombre y el otro se refiere a los seres celestes. Es curiosa la afinidad de este último con Decretum Gratiani, pars I, Distinctio 89, c. 7, cuya parte final reproduzco: «Quia vero creatura in una eademque qualitate gubernari vel vivere non potest, celestium militiarum nos instruit, quia dum sunt angeli, sunt archangeli, liquet, quia non aequales sunt, sed in potestate et ordine (sicut nostis) differt alter ab altero».

${ }_{46}$ Nuevos escolios, I, p. 897; Escolios, I, p. 137: «El rango de nuestro adversario nos sitúa: ser vencedor o vencido es subalterno», y Escolios, II, p. 655: «La comunicación entre los hombres se dificulta al desaparecer los rangos.// Los individuos no se tienden la mano al caminar en tropel, sino se tratan a codazos».

47 Nuevos escolios, II, p. 1204: «La jerarquía es la sintaxis del discurso social».

${ }^{48}$ Escolios, II, p. 535: «Cuando las jerarquías desaparecen, no es tanto el caos, como la insulsez, lo que predomina»; surgen las «sociedades allanadas», podría decirse aprovechando la expresión de Textos, p. 79. Vid. también Escolios, I, p. 394: «Donde la sociedad carece de rangos, la ironía carece de eco».

49 Escolios, II, p. 574.

${ }^{50}$ Nuevos escolios, I, p. 934, y Sucesivos escolios, p. 1259. Vid. también los textos citados supra, en las notas 36 y 28 . 
de ordenación lo hemos llamado nosotros. Pero, sobre todo, el verbo «salvar» denota, igual que en un comentario anterior, la idea de que la virtualidad del orden jerárquico no consiste primariamente en destruir ni en acordar o absolver las contradicciones, sino en asumirlas y ordenarlas mediante la colocación de sus términos en los lugares adecuados. De este modo, siendo el conflicto una de las formas de contradicción entre términos diferentes (ricos y pobres, excelentes y mediocres, encumbrados y humildes, etc.), el orden jerárquico no lo ignora ni lo resuelve, simplemente atenúa la antítesis y evita sus consecuencias más perniciosas. ¿Cómo lo consigue?

La respuesta pasa necesariamente por la aspiración de totalidad que ya sugería uno de los últimos escolios citados en la sección anterior ${ }^{51}$. La idea es que el orden debe ser inclusivo, de manera que no deje fuera ninguno de los elementos del universo al que se refiere; se trata de una noción capital que se repite varias veces tanto en Notas como en los Escolios. Su expresión más acabada es la siguiente: «La totalidad sólo puede existir dentro de un orden jerárquico, porque allí y sólo allí infinitos términos coexistentes pueden durar sin excluirse y anularse, si pertenecen a órdenes distintos» ${ }^{52}$, o también esta otra: «Para que coexista una multiplicidad de términos diversos es necesario colocarlos en niveles distintos.// El orden jerárquico es el único que no expulsa ni suprime» ${ }^{53}$. Descendiendo a usos más especializados, también la encontramos aplicada a los objetos del mundo y a las funciones sociales ${ }^{54} \mathrm{o}$ en la caracterización de métodos diferentes, donde es de observar la identificación del método jerárquico con el principio mismo del orden ${ }^{55}$.

${ }^{51}$ Nuevos escolios, II, p. 1229: «El que sabe preferir no excluye.// Ordena».

52 Notas, p. 299.

53 Escolios, I, p. 94.

${ }^{54}$ Escolios, I, p. 448: «Ni hay en el mundo objeto insignificante, ni en la sociedad función tediosa, si colocamos los objetos en una escala ontológica y las funciones en una jerarquía sistemática.// Cada parte, en una totalidad ordenada, cuenta con el apoyo de las otras y tiene el orgullo de apoyarlas». Señala otro escolio que quien no acepta su rango se convierte en «mera ausencia de lo que no es», y después que «aun lo más modesto tiene en su sitio un precio inestimable» (Escolios, I, p. 198). La novedad que encontramos aquí consiste en atribuir a la naturaleza la fijación del rango de cada uno, lo que no parece conforme con la idea predominante en Gómez Dávila de la artificialidad del orden en general.

${ }^{5}$ Escolios, II, p. 500: «Lógica, dialéctica, paradoja, jerarquía.// Método lógico, que el principio de identidad regula. Método dialéctico que guía el principio de contradicción. Método paradójico, obediente al principio de coincidencia de los contrarios. Método jerárquico, que aplica el principio de ordenación.// El método jerárquico no identifica los términos, ni los absorbe, ni los equilibra, sino los ordena». Cfr. Escolios, II, p. 494: «El método dialéctico parece inventado para eludir la obligación de colocar cada cosa en su sitio impuesta por el método jerárquico»; Escolios, II, p. 780: «Método dialéctico es la estrategia de una 
En relación con la sociedad, el resultado último de la idea de totalidad es que «sólo una estructura jerárquica es compasiva con los mediocres y los humildes», dado que es la única que los abraza y les proporciona un lugar ${ }^{56}$. Pero el problema no es sólo de compasión, sino que del orden jerárquico e integrador se espera el freno eficaz a la violencia, ya sea la que proviene de la autoridad ${ }^{57}$, ya se trate, cabe entender también, de una difusa violencia social ${ }^{58}$. Por un lado, esto es así porque en la sociedad, igual que en el alma, «cuando las jerarquías dimiten los apetitos mandan» ${ }^{99}$; es decir, asoma el bárbaro y, por último, el animal, ese simio adormilado en cada hombre del que se habla en $\operatorname{Textos}^{60}$. Y por otro, porque la sociedad no jerarquizada se fragmenta ${ }^{61} \mathrm{y}$ porque la clave de la justicia - como ya antes se nos ha sugerido- es la jerarquía ${ }^{62}$. Pero la estructura jerárquica tiene al menos otras dos galas todavía, siendo la primera de ellas que en una sociedad de este tipo no se confunde el rango con el individuo - éste es considerado por lo que es-, mientras que en las sociedades igualitarias «los "superiores" se creen superiores» o, por decirlo con el mismo lenguaje, confunden su rango con su individuo ${ }^{63}$. La otra, en cuya

rebeldía que se enclaustra en la inmanencia.// Método jerárquico es el esquema de una pesquisa dócil a las articulaciones del universo», y Nuevos escolios, I, p. 886: «El absolutismo, intelectual o político, es el pecado capital contra el método jerárquico.// Usurpación, por uno de los términos de un sistema, de los fueros de los otros».

56 Escolios, I, p. 424, el texto completo dice así: «En sociedades donde todos se creen iguales, la inevitable superioridad de unos pocos hace que los demás se sientan fracasados.// Inversamente, en sociedades donde la desigualdad es norma, cada cual se instala en su diferencia propia sin sentir la urgencia, ni concebir la posibilidad, de compararse.// Sólo una estructura jerárquica es compasiva con los mediocres y los humildes». Nótese de pasada que la igualdad de todos es una «creencia» que no se corresponde con el dato real e inexorable de la superioridad de algunos. Cfr. Nuevos escolios, II, p. 1173: «Donde las costumbres y las leyes les permiten a todos aspirar a todo, todos viven frustrados cualquiera que sea el sitio que lleguen a ocupar».

57 Escolios, II, p. 802: «Al desaparecer las jerarquías la autoridad se convierte en violencia desnuda o violencia larvada».

58 Nuevos escolios, I, p. 1035: «La indemostrabilidad de la verdad nos pide estructuras que den la más amplia cabida al error.// Jerarquicemos para no recurrir a la violencia», y Nuevos escolios, II, p. 1240: «De las opciones abruptas no nos defienden sino las soluciones jerárquicas».

59 Nuevos escolios, I, p. 893. Cfr. Notas, p. 70: «En una sociedad nivelada e igualitaria el poder pertenece irrestrictamente a la mayoría, que siempre identifica la libertad con el cumplimiento de sus deseos».

${ }^{60}$ Textos, p. 81.

${ }^{61}$ Escolios, I, p. 618: «Toda sociedad no jerarquizada se parte en dos» (esas dos partes son la minoría de los poderosos y la masa de los sometidos).

${ }_{62}$ Escolios, II, p. 640: «Si no jerarquizamos, acabamos siendo injustos con todo.// Hasta con lo que fuimos o con lo que somos» Vid. supra, nota 32.

${ }_{63}$ Nuevos escolios, I, p. 976: «En una sociedad jerárquica no se le ocurre a nadie con- 
exposición Gómez Dávila introduce explícitamente el perspicaz punto de vista del reaccionario, consiste en acotar el peligro que supone «la presencia de bobos en los más altos rangos» ${ }^{64}$, aunque el sentido completo de esta ironía sólo se comprenderá más adelante, cuando abordemos una descripción más precisa del modelo de sociedad jerárquica en el que piensa Gómez Dávila. Por ahora podemos dejar que esos bobos se gusten y presuman, confortados nosotros por la esperanza de que pueda haber una forma de hacerlos inocuos.

Todavía dentro de la esfera de lo social en sentido amplio, las glosas gomezdavilianas emparejan la jerarquía con la libertad y con la educación y el respeto, y también, por supuesto, con la igualdad, aunque este tema debe quedar para la última sección de nuestro trabajo.

Por lo que toca a la libertad, ofrece un buen punto de arranque la sintética afirmación de que «sin estructura jerárquica no es posible transformar la libertad de fábula en hecho» ${ }^{65}$. Esta convicción es temprana en Gómez Dávila, que la expone ya en Notas ${ }^{66}$ con más amplio desarrollo verbal subrayando la necesaria presencia de una «jerarquía de poderes, de privilegios y de libertades» en una sociedad «ordenada para la libertad ${ }^{67}$. La jerarquía aludida se traduce en Escolios en dispersión de poder, creadora de una «pirámide de libertades»; el término opuesto es la concentración del poder de la sociedad igualitaria, que sólo permite ser libre «al dueño del poder supremo» ${ }^{68}$. Y en la medida en que igualitarismo

fundir el rango con el individuo.// En las democracias, al contrario, los "superiores" se creen superiores». Cfr. Nuevos escolios, II, p. 1206: «La ausencia de jerarquías legales facilita el ascenso de los menos escrupulosos» (que hayamos sabido ver, éste uno de los pocos casos de conexión explícita de la jerarquía con la órbita de la ley). Cfr. Escolios, II, p. 598: «Dos condiciones son necesarias para que una aristocracia nazca: que las leyes no lo impidan y que no lo faciliten».

${ }_{64}$ Escolios, II, p. 679: «Como sabe la importancia para la sociedad de la estructura jerárquica en sí, la presencia de bobos en los más altos rangos no escandaliza al reaccionario.// El "elitismo" es tesis democrática».

${ }^{65}$ Nuevos escolios, I, p. 932; la segunda parte reza así: «El liberal descubre siempre demasiado tarde que el precio de la igualdad es el Estado omnipotente».

${ }^{66}$ Como es bien sabido, Notas se publicó en México en 1954. Para los interesados en el proceso del pensamiento de Gómez Dávila, se deduce de aquí una información «cronológica» que podría revestir cierto interés; un simple apunte: la primera edición de la obra de Hans Barth, Die Idee der Ordnung (op. cit. supra, nota 15), que Gómez Dávila tenía en su biblioteca, es de 1958.

${ }^{67} \mathrm{Vid}$. supra, nota 35, y texto correspondiente. La idea general se encuentra en Escolios, II, p. 793: «Ś́lo jerarquizando podemos limitar el imperialismo de la idea y el absolutismo del poder».

${ }^{68}$ Escolios, II, p. 650: «La concentración del poder en la sociedad igualitaria no le permite ser libre sino al dueño del poder supremo.// La dispersión del poder en la sociedad jerar- 
e individualismo suelen ir de la mano, la jerarquía —el tipo de jerarquía aludido - se opone al totalitarismo, del que el aislamiento de los individuos no es sino condición ${ }^{69}$. Sólo dentro de ella tiene cabida el individualismo consecuente, a saber, aquel, precisamente, que «proclama la diversidad y concluye en jerarquía» ${ }^{70}$. Se entiende por lo anterior que la libertad no es anhelo de muchedumbre homogénea, sino urgencia de individuos concretos sólo factible en la sociedad jerarquizada ${ }^{71}$; requisito de ella es el libre sometimiento en alternativa a la violencia que se desata para reprimir las insurrecciones de un $\mathrm{alma}^{72}$ que busca a ciegas su esclavitud. Ahora bien, esas insurrecciones ¿'son lo mismo que las «convulsiones libertarias» de un escolio anterior? ${ }^{73}$ Por mucho que pueda existir una relación entre ellas, es más probable que se trate de cosas distintas: el campo de batalla contra el desorden es ante todo el hombre, y la insurrección y la violencia que lo reprime son fenómenos internos del alma de cada cual ${ }^{74}$; ahí es donde comienza a gestarse la convulsión que acabará trastornando a la sociedad. De cualquier modo, recuérdese también lo dicho más arriba respecto del balance entre orden y desorden del que nace la libertad ${ }^{75}$.

quizada, en cambio, crea una pirámide de libertades.// La sociedad igualitaria alterna épocas de parálisis con periodos de convulsiones libertarias.// El individuo de la sociedad jerarquizada, a la inversa, no necesita rebelarse para ser libre, ni se envilece porque no se rebela».

${ }_{69}$ Nuevos escolios, I, p. 982: «El individualismo no es antítesis del totalitarismo, sino condición.// Totalitarismo y jerarquía, en cambio, son posiciones terminales de movimientos contrarios»; en qué consista esa condición del totalitarismo lo explica un comentario anterior que menciona la petrificación del individuo en «mónada hermética» o su disolución en «fango colectivo» (vid. supra, nota 40). Cfr. Nuevos escolios, II, p. 1220: «En la sociedad jerárquica la fuerza de la imaginación se disciplina y no desorbita al individuo como en la sociedad democrática». Muy lejos, en principio, de los presupuestos y de las intenciones de Gómez Dávila, un conocido filósofo español enuncia en nuestros días un diagnóstico muy parecido sobre la sociedad contemporánea: «El apogeo del subjetivismo adopta la forma de la despersonalización». Vid. J. Gomá LANZón, Ejemplaridad pública, Madrid, Taurus, 2014, pp. 296 y s.; para una explicación un poco más detenida vid. infra, el texto correspondiente a la nota 205.

${ }^{70}$ Nuevos escolios, p. 1090; por el contrario, «el individualismo inconsecuente proclama la similitud y concluye en democracia».

${ }^{71}$ Escolios, I, p. 72: «Una muchedumbre homogénea no reclama libertad.// La sociedad jerarquizada no es meramente la única donde el hombre puede ser libre, sino también la única donde le urge serlo».

72 Escolios, II, p. 700: «Las estructuras jerárquicas se desploman cuando el hombre, en lugar de la subordinación libre, prefiere la violencia que reprime las insurrecciones serviles del alma».

73 Vid. supra, nota 68

${ }^{74}$ Cfr. Escolios, I, p. 382: «La lucha contra el desorden es más noble que el orden mismo.// El hombre dueño de sí mismo no es tan magnánimo como el que reprime la insurrección de su alma.// El más hondo silencio es el de una muchedumbre aterrada».

75 Vid. supra, notas 33-36, y texto correspondiente. 
Sobre la educación y el respeto ${ }^{76}$, Gómez Dávila ofrece una definición en sentido propio que presupone la jerarquía y sugiere, por otro lado, que la buena educación se manifiesta, sobre todo, en la relación con los iguales: «Llámase buena educación los hábitos provenientes del respeto al superior transformados en trato entre iguales ${ }^{77}$. Tintes definitorios tiene también esta otra frase: «La buena educación no es, finalmente, sino la manera como se expresa el respeto», primera cláusula de un comentario más largo que contiene a su vez la definición del respeto — «un sentimiento que la presencia de una superioridad admitida infunde»—y la indicación de que la jerarquía es substrato del mismo ${ }^{78}$. Según el primer texto, la educación para el trato entre iguales es el conjunto de hábitos adquiridos en el respeto a los superiores. De acuerdo con el segundo, el respeto a los superiores (por parte de los inferiores, por tanto) se asienta en el acatamiento de jerarquías reales o ficticias y en la interiorización, inducida por él, del dato en sí de la superioridad. Todo depende, así pues, de la estructura superiorinferior, de donde la diferencia que constata otro escolio entre la sociedad igualitaria de nuestros días y la sociedad jerarquizada: «Educar es hoy una tarea especializada y problemática. Una sociedad jerarquizada, en cambio, educa espontáneamente» ${ }^{79}$.

¿Quién es el inferior y cómo ha de ser la superioridad idónea para educarlo? Que nos interesemos por lo primero podría extrañar al lector, pero tiene sentido puesto que hay un escolio que alude implícitamente al inferior bajo la veste del inculto, aunque acaso una lectura de este tipo, que toma ambos términos como totalmente coextensivos, sea demasiado reductiva, sobre todo por la sospecha de que el inferior pueda ser, de forma más general, el mediocre o el humilde que sólo el orden jerárquico encuentra modo de acoger. En todo caso, ese mismo comentario

${ }^{76}$ Merece la pena observar que los comentarios relativos a esta cuestión son todos del primer volumen de los Escolios.

77 Escolios, I, p. 102.

${ }^{78}$ Escolios, I, p. 336: «La buena educación no es, finalmente, sino la manera como se expresa el respeto.// Siendo el respeto, a su vez, un sentimiento que la presencia de una superioridad admitida infunde, donde falten jerarquías, reales o ficticias, pero acatadas, la buena educación perece.// La grosería es producto democrático».

79 Escolios, I, p. 111. Refiere Montaigne - uno de los «santos patrones» de Gómez Dávila (Escolios, I, p. 409) - que su padre lo envió desde la cuna a que lo criaran en una pobre aldea de sus dominios y lo mantuvo allí durante la lactancia y aun después para que se acostumbrara a la «forma de vida más humilde y común», pero el gesto, además de infrecuente, seguramente no fue espontáneo en el sentido de este escolio. Cfr. M. DE MonTAIGNE, Ensayos, ed. bilingüe, trad. y notas de J. YAGÜE Bosch, Barcelona, Galaxia Gutemberg, 2014, pp. 2138-1240 (1239-1241). 
considera necesaria la reunión casual en el mismo sujeto de dos clases de superioridad - la «legítima» y la «social» o «mundana»- a fin de que el inculto, que sólo acata la segunda, pueda acabar educándose; este proceso se describe en términos de un «tránsito de la fascinación a la obediencia y del embobamiento social a la imitación civilizadora». No me resisto a observar que, conforme a mi experiencia de profesor en una sociedad con ínfulas igualitarias, del prestigio social van quedando solamente restos como de un naufragio y que la superioridad legítima es constantemente socavada por quienes controlan los mecanismos que podrían y deberían fortalecerla. Al final, el escolio que comento repite esencialmente el motto anterior acerca de la distinta eficacia educativa de la sociedad igualitaria y de la sociedad jerarquizada ${ }^{80}$.

Las condiciones de superior e inferior se mencionan profusamente a propósito de la educación, pero es evidente que éste es sólo uno de los ámbitos de la sociedad en los que se puede dar su existencia. Con relación a cualquiera de ellos, sin duda es importante observar que la superioridad de la que habla Gómez Dávila es la del hombre que no siente necesidad de hacérsela perdonar, de igual modo que la inferioridad a la que se refiere tampoco siente vergüenza de $s^{1}{ }^{81}$. Y es importante, asimismo, advertir que, con independencia del rango de cada uno en la escala jerárquica, la existencia de ésta es crucial para todos por la razón indicada en un magnífico escolio que dice, trastocando la perspectiva usual, nada menos que lo siguiente: «El alma bien nacida admite la existencia de inferiores, para que no la igualen a los superiores que admira» ${ }^{82}$.

Por lo demás, puesto que el orden es máximamente jerarquía, la necesidad de jerarquizar aflora por doquier sin restringirse a los asuntos

${ }^{80}$ Escolios, I, p. 188: «Como el inculto no acata más superioridad que la superioridad social, la superioridad legítima no educa si un adventicio prestigio social no la sustenta.// Se requiere que el azar confiera al mismo ser la superioridad mundana y la legítima, para que se establezca un tránsito de la fascinación a la obediencia y del embobamiento social a la imitación civilizadora.// Si la sociedad jerarquizada no educa necesariamente, la sociedad igualitaria no puede jamás educar». Cfr. Sucesivos escolios, p. 1338: «Civilización es la disciplina que una clase social alta le impone, con su sola existencia, a una sociedad entera».

${ }^{81}$ Nuevos escolios, I, p. 883: «Ni la inferioridad es vergonzosa, ni la superioridad culpable». Cfr. Nuevos escolios, I, p. 1030: «Nadie es ridículo en su sitio; cualquiera en sitio ajeno», y Sucesivos escolios, p. 1374: «Considerar iguales todas las profesiones no es menos contrario a la realidad que el igualitarismo individual.// La civilización exige que las profesiones se coloquen en orden jerárquico».

${ }^{82}$ Escolios, I, p. 105. Por la amplitud con que se utiliza — para adjetivar el alma, sin más-, parece claro que la locución «bien nacida» no se refiere a la persona de noble linaje, sino a la que obra con nobleza. Cfr. Nuevos escolios, II, p. 1069: «Noble no es el que cree tener inferiores, sino el que sabe tener superiores». 
ya vistos. En realidad, la jerarquía es mandamiento axiológico ${ }^{83}$; existe una jerarquía de bienes ${ }^{84}$ y una jerarquía (teórica) de fines ${ }^{85}$, se necesita la ordenación jerárquica de los valores para hacer sitio a su diversidad radical $^{86}$ y no hay expresión plena de individuo o valor en la que no se exprese su rango ${ }^{87}$. La jerarquía es también, en más de un sentido, disposición metódica para conocer y justipreciar ${ }^{88}$, y es igualmente, aunque en un plano distinto, valor estético ${ }^{89}$. Su peor enemigo es el igualitarismo porque oscurece no ya su existencia efectiva, sino su misma noción ${ }^{90}$.

\section{EL MODELO GOMEZDAVILIANO DE SOCIEDAD JERÁRQUICA (O JERARQUIZADA)}

Después de haber visto la importancia atribuida por Gómez Dávila a la jerarquía, tanta que hace de la locución «orden jerárquico» poco menos que una tautología, nos corresponde repasar los pasajes que dibujan el perfil de lo que él pudo considerar un modelo histórico de sociedad jerarquizada. El punto no es baladí porque, aunque sabemos bien que el reaccionario auténtico no propone ni se propone la recuperación del

${ }_{83}$ Nuevos escolios, I, p. 964: «El absolutista anhela una fuerza soberana que sojuzgue a las otras, el liberal una multitud de fuerzas débiles que se neutralicen mutuamente.// Pero el mandamiento axiológico decreta jerarquías de fuerzas múltiples, vigorosas y actuantes».

${ }^{84}$ Escolios, I, p. 275: «La idea misma de sacrificio parece absurda a quienes ignoran que existe una jerarquía de bienes».

${ }^{85}$ Notas, p. 288.

${ }_{86}$ Nuevos escolios, p. 1136: «La reducción sistemática de todos los valores a uno solo es imposible. Su diversidad radical lo impide.// Sólo es posible la ordenación jerárquica donde espontáneamente se subordinan». Cfr. Escolios, I, p. 167: «Donde se reconozca una jerarquía de valores objetivos, el capricho no es peligroso. Cualquier cosa puede lícitamente fascinarnos si no alteramos su rango». En Textos, p. 103, se dice que «cada civilización es una actitud básica que ordena una jerarquía de valores».

${ }^{87}$ Nuevos escolios, II, p. 1138: «El historismo no es relativista sino para el que olvida que la desaparición de criterios externos, anticipados, absolutos, no coloca a todo individuo y a todo valor en igual sitio, ya que en la expresión plena de cada individuo y de cada valor está expresado su rango».

${ }^{88}$ Escolios, I, p. 319: «Quien repudie el dogmatismo tiene que escoger entre indiferentismo y jerarquía»; Escolios, II, p. 690: «Entre los postulados también existen jerarquías.// Hay postulados para visión perfecta, postulados para miopes, postulados para ciegos»; Nuevos escolios, I, p. 1043: «Al análisis trivial se le olvida jerarquizar las partes que distingue», y Sucesivos escolios, p. 1336: «Frente a la pluralidad de civilizaciones y culturas, no debemos ser ni relativistas ni absolutistas, sino jerarquizantes».

${ }^{89}$ Nuevos escolios, II, p. 1218: «Disciplina, orden, jerarquía, son valores estéticos».

90 Nuevos escolios, I, p. 1046: «La trascendencia se convierte en dualismo y el dualismo en maniqueísmo, donde el igualitarismo eclipsa la noción misma de jerarquía». 
pasado $^{91}$, la efectividad de tal modelo, precisamente por el hecho de pertenecer a una experiencia concluida del todo, subraya su viabilidad potencial ${ }^{92}$. Es como una advertencia que nos recordara que la cosa, puesto que fue, podría volver a ser.

Dos conceptos clave condensan la esencia del modelo gomezdaviliano que queremos examinar: feudalismo y aristocracia. No es necesario ningún esfuerzo especial para mostrar que la entraña de ambos consiste en la estructura superior-inferior, o lo que es lo mismo, en la jerarquía.

\section{Feudalismo}

Por tercera vez en este trabajo traemos a colación un pasaje de Notas que describe el modelo sin darle todavía un nombre concreto. Se trata, en todo caso, del modelo de una «sociedad ordenada para la libertad»y del único modelo que puede garantizar «una libertad soberana y real»; en él habría «una jerarquía de poderes, de privilegios y de libertades», generadora de «una tal diversidad de situaciones» que impediría la realización de «ninguna uniformidad de deseos». Si hay algo que debe anhelar «un espíritu sinceramente liberal» es la presencia manifiesta de lo anterior en el cuerpo político ${ }^{93}$. Por otra parte, puesto que la libertad sólo prospera en un medio donde se combinan orden y desorden ${ }^{94}$, necesario es preguntar cómo pueda ser esto. Nos lo dice la segunda parte de un escolio que, esta vez sí, nombra la formación socio-política que acertó a realizar semejante combinación, a la vez que califica de milagro la consecución de la misma: «Inscribir un desorden instituido dentro de un orden englobante

91 Vid., por ejemplo, Textos, p. 159 (cfr. Nuevos escolios, p. 997): «El reaccionario no es el soñador nostálgico de pasados abolidos, sino el cazador de sombras sagradas sobre las colinas eternas»; Escolios, II, p. 578: «No es una restauración lo que el reaccionario anhela, sino un nuevo milagro»; Escolios, II, p. 856: «El reaccionario es el guardián de las herencias.// Hasta de la herencia del revolucionario»; Escolios, II, p. 858: «No pertenezco a un mundo que perece.// Prolongo y transmito una verdad que no muere», y Nuevos escolios, II, p. 1119: «El reaccionario no aspira a que se retroceda, sino a que se cambie de rumbo.// El pasado que admira no es meta, sino ejemplificación de sus sueños». Téngase en cuenta, además, que «cuando un reaccionario habla de "unvermeidliche Restauration", no debemos olvidar que el reaccionario calcula en milenios», según se advierte en Escolios, II, p. 756.

92 Cfr. Nuevos escolios, II, p. 1144: «Ningún pasado es ideal.// Pero sólo del pasado surgen ideales que no sean linfáticos, ideales con sangre en las venas».

${ }_{93}$ Notas, p. 70. Cfr. M. RabieR, «Nicolás Gómez Dávila y las paradojas del conservadurismo», La Razón Histórica. Revista hispanoamericana de Historia de las Ideas, núm. 26 (2014) pp. 229 y s.

${ }^{94}$ Cfr. supra, notas 32-33, y texto correspondiente. 
fue el milagro del feudalismo» ${ }^{95}$. El contenido es densísimo. «Desorden instituido» parece casi un oxímoron; la expresión había sido utilizada por Bertol Brecht en una obra de 1930 (Die Ausnabme und die Regel) que Gómez Dávila poseía ${ }^{96}$, pero la intención con que la usa el colombiano difícilmente puede coincidir con la del dramaturgo alemán ${ }^{97}$. «Orden englobante» alude quizás a la nota de totalidad que hemos visto en otros escolios, o acaso meramente a la inscripción del desorden dentro del orden. ¿Y qué significa «inscribir»? Según la acepción que parece más apropiada, se trata de trazar una figura dentro de otra, de manera que tengan puntos comunes sin cortarse.

Ya que se dice que el feudalismo fue la realización del milagro, para saber en qué consintió éste sería necesario hacerse una idea acerca del desorden inscrito dentro del orden y acerca de la transacción que pudo darse entre ellos. Intento formular una hipótesis. Como es lógico, dadas las concepciones de Gómez Dávila, el desorden de un determinado sector, ámbito o espacio social implica la negación de la jerarquía en su seno. Por otra parte, desorden no significa inexistencia de orden, sino perturbación del orden de antemano existente: es por relación a él como el desorden adquiere un sentido. Partiendo de estas premisas, desorden «instituido» podría no significar mucho más que desorden no refutado, sino asumido, e instituido, entonces, en la medida en que acepta limitarse y contenerse dentro del orden global sin llegar a desafiarlo, quiero decir, sin amenazar su contextura específicamente jerárquica. En el feudalismo, lo común de ambas figuras - el orden que engloba y el desorden inscrito en él- no consistiría tanto en tales o cuales aspectos o elementos concretos, sino en el hecho de su tolerancia recíproca y su mutua combinación. Lo común, en definitiva, sería el feudalismo en cuanto tal, formación sociopolítica de estampa definida y unitaria, duradera pero no estacionaria, dinámica pero sin crispación ${ }^{98}$.

${ }^{95}$ Escolios, II, p. 841. En Sucesivos escolios, p. 1324, se alude al feudalismo en estos términos: «Ciertas instituciones políticas — muertas y sepultadas - conservan valor intemporal de paradigma»

${ }_{96}$ Formando parte de B. BRECHT, Stücke für das Theater am Schiffbauerdamm, 1928-1933, Berlin, Suhrkamp, 1955-1964.

${ }_{97}$ «Os lo pedimos encarecidamente:// ¡No creáis natural lo que se produce sin cesar!// Que en una época tal de confusión sangrienta// De desorden instituido, de arbitrariedad planificada// De humanidad deshumanizada,// Nada sea tomado como natural, para que nada// Pase por inmutable».

${ }^{98}$ Cfr. las precisiones de Escolios, I, p. 196: «Tanto la Bauernkrieg del XVI, como las sublevaciones campesinas del XVII y del XVIII, fueron insurrecciones contra la sociedad moderna. La población no se levantó contra el feudalismo, sino contra el mundo que lo estaba reemplazando.// El espíritu mercantil usurpó costumbres jurídicas del sistema antagónico y convirtió usos legítimos en abusos insufribles». 
Antes de seguir adelante, conviene traer a colación una interesante observación de Carl von Clausewitz cuyo núcleo es consonante del todo con el concepto general que se extrae de los textos gomezdavilianos. Se trata de lo siguiente: «Las grandes y pequeñas monarquías de la Edad Media hacían la guerra con ejércitos feudales [...] El ejército feudal estaba constituido por medio de la jerarquía del vasallaje [...] En general, no ba habido jamás una época en que la cohesión de los Estados fuese tan débil y en que cada ciudadano fuese tan independiente» ${ }^{99}$. Viniendo de pluma tan reconocida, sin duda es muy importante esta constatación. En efecto, enunciada a la altura de 1832, cuando se publica el tratado Vom Kriege del gran soldado prusiano y prestigioso teórico de la ciencia bélica —en un momento, por otro lado, en el que, si queda algo del feudalismo, son únicamente residuos en vías de desaparición-, esa memoria tan precisa que sobrevive de él garantiza que el aprecio de Gómez Dávila por el orden feudal no es fruto meramente del temperamento antimoderno de un pensador reaccionario. La opinión de Von Clausewitz es muy valiosa en sí misma, no en último lugar porque proviene de una obra célebre que la recoge como al paso y la da por descontada. Pero ideas muy parecidas y más circunstanciadas sobre el feudalismo expone también, más o menos por la misma época, un significado aristócrata francés, liberal y escritor político por el que Gómez Dávila siente especial predilección: el vizconde Alexis de Tocqueville ${ }^{100}$. En los lugares oportunos iremos señalando las afinidades que nos parezca notar entre las afirmaciones del colombiano y los comentarios del autor de La democracia en América.

Entrando ahora sí en los escolios, es conveniente advertir que su aproximación al feudalismo tiene lugar desde flancos distintos. Por ejemplo, el de la descripción, que se presenta objetiva pero encierra siempre el encomio y, como no podía ser de otro modo, se expresa regularmente

${ }^{99}$ C. Von Clausewitz, De la guerra, Barcelona, Books4pocket, 2015, p. 755 (la cursiva es nuestra). Vom Kriege, Achtes Buch, Drittes Kapitel B: Von der Größe des kriegerischen Zweckes und der Anstregung: «Die großen und die kleinen Monarchien des Mittelalters führten ihre Kriege mit Lehnsheeren (...) Das Lehnsheer selbst bestand aus einer Einschachtelung von Vasallentum (...) Überhaupt hat es nie eine Zeit gegeben, wo der Staatsverband so locker und der einzelne Staatsbürger so seibständig war», disponible en bttp://www.clausewitz.com/readings/VomKriege1832/TOC.htm. En edición de 1914, Gómez Dávila contaba con esta obra en su biblioteca.

${ }^{100}$ Cfr. A. DE Tocqueville, La democracia en América, ed. y trad. de E. Nolla, Madrid, Trotta, 2010, pp. 128 y s., 249, 370, 532 y ss., y 930 y s. Diametralmente contraria es la visión de A. Hamilton, The federalist, 1. ${ }^{a}$ ed., New York, 1788 [vid. en español, R. Márz (ed.), El federalista, Madrid, Akal, 2015, pp. 182 y s.]. 
con verbo conjugado en pretérito. El feudalismo ${ }^{101} \mathrm{o}$ «pluralismo feudal» fue «una articulación libre de mecanismos sociales» que, asociado a otros factores afines ${ }^{102}$, frenó temporalmente «la fosilización totalitaria del organismo social bajo la presión del Estado». En este punto es necesario advertir que para Gómez Dávila el Estado es esencialmente totalitario ${ }^{103}$ : la dilación durante varios siglos de su tendencia espontánea al despotismo total fue solamente «una milagrosa primavera» ${ }^{104}$ enfriada a la larga por el conflicto entre el Papado y el Imperio, y cuyos restos, fragmentos del «tapiz de Occidente», han tardado siglos en desaparecer ${ }^{105}$.

La descripción del feudalismo como «articulación libre de mecanismos sociales» anota un previo «desvanecimiento del Estado», sustituido por el nuevo orden feudal que se instala en el espacio que aquél ya no es capaz de ocupar. Implícitamente parece negarse la condición estatal del feudalismo o, como mínimo, se rechaza su reducción a forma de Estado. Ahora bien, ¿cuál fue el Estado anterior reemplazado por el orden feudal? Si bien con limitación a la Pars Occidentis, no cabe sino pensar en el Estado romano bajo-imperial; de hecho, un comentario considera a la sociedad feudal legataria - ¡no heredera! - del ordo senatorius ${ }^{106}$, mientras que otro no muy lejano atribuye a Constantino el Grande el mérito de haber trazado «los cimientos de Occidente» con la revitalización de aquel ordo y tira una línea recta entre este hecho histórico y un tipo de sociedad, como fue la feudal, que «jerarquizaba en Sacro Imperio su estructura de barricadas libertarias» ${ }^{107}$. No es nimio el dato de que los dos textos se refieren a la «sociedad feudal» y no hablan de Estado sino, en todo caso, el primero

101 Combinamos tres comentarios: Escolios, II, p. 759; Escolios, II, p. 847, y Nuevos escolios, II, p. 1084. Sobre lo que sigue vid. L. GAROFALO, «Roma e i suoi giuristi nel pensiero di Nicolás Gómez Dávila», RGDR, núm. 24 (2015), pp. 17 y ss.

102 El dualismo imperium-sacerdocium, el episcopado, la nobleza territorial, el monaquismo y el patriciado urbano. Cfr. Escolios, I, p. 411: «La civilización de Occidente fue el resultado de una alianza entre terratenientes y obispos».

103 Escolios, II, p. 759, y Textos, pp. 76 y ss.

104 De nuevo esta idea de suceso extraordinario e inexplicable.

105 Algo sobrevive todavía: «Los parlamentos, en el Estado moderno, son rezagos feudales que tienden a desaparecer» (Sucesivos escolios, p. 1281).

106 Orden senatorial es justamente el ejemplo elegido por el DRAE para ilustrar la octava acepción de la palabra «orden»: «en determinadas épocas, grupo o categoría social».

107 Respectivamente, Nuevos escolios, I, pp. 947 y 969. Para un comentario más amplio vid. F. Cuena Boy, «Nicolás Gómez Dávila, la historia...», op. cit., pp. 8 y s.; íD., «Inventario de cosas relativas a Roma en los escritos de Nicolás Gómez Dávila y breve exposición de algunas de ellas», Annaeus. Anales de la tradición romanística, en prensa, \$5, y L. GAROFALO, «Roma e i suoi giuristi nel pensiero...», op. cit., pp. 21 y s. 
de ellos, de estructura socioeconómica ${ }^{108}$; hay ahí un fuerte indicio de comprensión diferenciada del feudalismo en el sentido de que no fue Estado, sino freno al avance del mismo.

La «estructura de barricadas libertarias» de la sociedad feudal —esa «articulación libre de mecanismos sociales»- supone, por tanto, una defensa eficaz contra la metástasis totalitaria del Estado. No ya en el plano de la descripción valorativa, sino en de la pura calificación, claramente lo repite otro texto según el cual «el único régimen político que no se inclina espontáneamente hacia el despotismo es el feudal» ${ }^{109}$. Podrá darse el avance del despotismo, de hecho se dio, y el cómo y el por qué serían buen tema para otro estudio. Pero lo que destaca este comentario es que el feudal es el único «régimen político» —nótese la nueva denominación, más cerca de la idea de Estado- que no participa de por sí de esa tendencia. Otro escolio que identifica la «era liberal» con «los cuatro siglos que duró la liquidación de las libertades medievales» ${ }^{110}$ plantea una pregunta difícil de responder con exactitud: ¿cuáles son esos siglos en los que piensa Gómez Dávila? Dado que el proceso aludido consiste en la anulación paulatina de la libertad feudal, una hipótesis no del todo improbable es que el colombiano situara su inicio en el mismo momento en que, según su opinión, nace el Estado moderno, o sea, el 7 de septiembre de 1303, con el ultraje de Anagni sufrido por el pontífice Bonifacio VIII ${ }^{111}$. Si fuera así, los cuatro siglos por los que nos preguntamos llegarían con bastante aproximación hasta la muerte del emperador Carlos VI de Alemania (1711-1740), un hecho que, por su parte, marca un hito importante en la historia del Sacro Imperio. Éste perdurará todavía hasta 1806, pero en trance de destrucción intestina, y no está de más recordar que para Gómez Dávila la sociedad feudal y el Imperio formaban una especie de unidad necesaria.

En la aproximación al feudalismo aflora por momentos el punto de vista jurídico. Lo más interesante desde este enfoque es la idea de que el

${ }^{108}$ En el mismo sentido vid. Nuevos escolios, II, p. 1008: «La difusión de la economía senatorial por la Pars Occidentalis del Imperio fundó la civilización de Occidente.// Las huellas del Senado romano no se borran finalmente sino en el siglo XX». En Nuevos escolios, II, p. 1084, la terminología es aún más clara: «esquema social», «estructura social» y «complejo social».

${ }^{109}$ Escolios, II, p. 677. Con base en otro escolio antes citado cabe entender en éste una referencia al despotismo «total», que viene a ser el nombre alternativo del totalitarismo.

${ }^{110}$ Escolios, II, p. 759. Esos cuatro siglos han de ser los mismos «varios siglos» que han sido necesarios para destruir el «tapiz de Occidente».

111 Vid. Textos, p. 76. Cfr. Escolios, II, p. 578: «Personalmente, sólo creo legítimo un mundo que presidan, desde tronos simétricos, Pontífice Romano y Emperador Germánico». Sobre este episodio histórico (la «bofetada» de Anagni) vid. E. CORTESE, Le grandi linee della storia giuridica medievale, Roma, Il Cigno Galileo Galilei, 2000, pp. 353 y ss. 
feudalismo es el único tipo de sociedad que tuvo «un contrato social por raíz histórica y por resorte ético» ${ }^{112}$. Su importancia reside sobre todo en que ofrece la posibilidad cierta de conectar la sociedad feudal con la concepción gomezdaviliana del derecho como convenio ${ }^{113}$. Otra glosa subraya que el superior es «amparo», en vez de «peso», «sólo cuando la pirámide social es jerárquica jurídicamente», o sea, cuando no se queda en «mero resultante empírico de casualidades sociales» ${ }^{114}$. Parece plausible entender una alusión a la ventaja de juridificar los efectos del dinamismo social, siempre bajo el prisma del derecho consuetudinario que la recordada concepción de lo jurídico instala en su centro. Menos explícita, por último, se presenta a primera vista la idea de que los «derechos del hombre» se originan en «el connubio de la cristiandad con el feudalismo» ${ }^{115}$. Con todo, nos da pie para introducir una serie de textos que acabarán de proporcionarnos una imagen más definida de aquello que otros pasajes ya vistos describen como «articulación libre de mecanismos sociales», como «estructura de barricadas libertarias» o, simplemente, como «desorden instituido dentro de un orden englobante».

Para no regresar a esa página de Notas ya varias veces citada sobre «una sociedad ordenada para la libertad», partimos ahora de Textos, donde se pormenorizan los atributos peculiares del estado medieval (sic) que suponen mayor contraste con la empresa democrática que acabará destruyéndolo: laberinto jurídico, libertad patrimonial de algunos, usurpaciones sancionadas de otros, fueros naturales de todos; y unas líneas después: poderes feudales, fueros provinciales, privilegios eclesiásticos y también lenta mutación de las costumbres y estructuras contractuales y pactadas. En síntesis, presencia eficaz de derechos precedentes al Estado y de libertades que eficazmente lo limitan ${ }^{116}$. Con plural significado - puesto que remite a una determinada

112 Escolios, I, p. 164.

113 Concepción desarrollada en un ensayo especial sobre derecho, justicia y Estado. Vid. N. Gómez Dávila, «De iure», Revista del Colegio Mayor de Nuestra Señora del Rosario (bomenaje a Nicolás Gómez Dávila), núm. 81/542 (1988), pp. 67-85. Sobre ella vid. F. CuENA Boy, «Nicolás Gómez Dávila, la historia...», op. cit., pp. 11 y ss., y 15 y s., y L. Garofalo, «Roma e i suoi giuristi nel pensiero...», op. cit., pp. 6 y ss.

${ }_{114}$ Nuevos escolios, II, p. 1040.

115 Sucesivos escolios, p. 1335. Gómez Dávila entrecomilla siempre la expresión «derechos del hombre»: «Lo inaceptable en los "derechos del hombre" es el nombre», dice el escolio inmediato.

116 Textos, p. 77. Parecidas consideraciones se encuentran en A. DE TocQueville, La democracia en América, op. cit., pp. 532 y ss. Sobre la democracia como posible texto implícito de los escolios y sobre la crítica gomezdaviliana de la «religión democrática» vid., por todos, J. M. Serrano Ruiz-Calderón, Democracia y nihilismo..., op. cit., cap. 5, pp. 203-242, passim. 
edad de la historia sin necesidad de nombrarla — un escolio declara que «las "libertades" son recintos sociales en los cuales el individuo se puede mover sin coacción alguna» ${ }^{117}$. Tales cercados (la palabra es exacta) encarnan la «libertad concreta» mencionada en otro escolio del que, supuesto que la libertad nace de una cierta proporción entre el orden y el desorden, podríamos rescatar el apelativo «anarquía feudal» y asignarlo sin demasiadas reticencias, pese al uso peyorativo que le dieron los ilustrados (Voltaire y Gibbon, por ejemplo) a la edad histórica de que se trata: la Edad Mediaa ${ }^{118}$. En el polo opuesto se sitúa la libertad abstracta e indistinta, aquella que al predicarse de todo sujeto excluye en realidad al sujeto, esto es, la «libertad principio metafísico» en la que cualquier imposición busca coartada ${ }^{119}$. Sobre su base se levanta el Estado, que «absorbe todas las libertades en la suya» y de este modo transforma el «aparato que la sociedad elaboró para su defensa en un organismo autónomo que la explota» ${ }^{120}$.

«Lo único que garantiza un buen gobierno es una estructura política y social que sólo permita gobernar un poco» ${ }^{121}$. Bajo este axioma se cobijan otras proposiciones que se refieren a su aplicación imperfecta e indican los efectos que acarrea su desplazamiento: «toda agrupación que no sea meramente autoritaria, es decir, toda agrupación donde existan entre superiores e inferiores responsabilidades recíprocas, asume formas

117 Sucesivos escolios, p. 1280. M. WeBER, Economía y sociedad. Esbozo de sociología comprensiva, 1. ${ }^{\text {a }}$ reimpr., Madrid, Fondo de Cultura Económica, 1993, pp. 810 y ss., ofrece una descripción amplia del feudalismo y su clases. Con enfoque influido por las premisas del materialismo histórico puede verse también E. MEIKsINS Wood, De ciudadanos a señores feudales. Historia social del pensamiento político desde la Antigüedad a la Edad Media, Madrid, Paidós, 2011, pp. 213 y ss.

${ }^{118}$ Escolios, II, p. 584: «"Anarquía feudal” es el apodo con que el terrorismo democrático denigra el único periodo de libertad concreta que conozca la historia», y Nuevos escolios, II, p. 1140: «Esa "anarquía feudal" que el liberal vulgar anatematiza regocija al liberal auténtico». En rigor, el periodo que los ilustrados denominan «anarquía feudal» comienza con la disgregación del Imperio a la muerte de Carlomagno. Todo en la Edad Media, incluidas las relaciones feudales, es «recio, sensual, concreto» (Escolios, II, p. 710).

119 Sucesivos escolios, p. 1280: «Las "libertades" son recintos en los cuales el individuo se puede mover sin coacción alguna; la "Libertad", en cambio, es principio metafísico en nombre del cual una secta pretende imponer a los demás sus ideales de conducta». En la misma página, un escolio anterior nos acerca la misma idea: «Donde desaparece hasta el vestigio de nexos feudales, la creciente soledad social del individuo y su creciente desamparo lo funden pronto en masa totalitaria». Cfr. Escolios, II, p. 718: «La esclavitud no tiene más alternativa duradera que el vasallaje».

${ }^{120}$ Escolios, II, p. 811; Nuevos escolios, II, p. 1141; el Estado, explica esta última glosa, «es la forma política antagónica del Imperio, estructura de irreductibles libertades»; Nuevos escolios, II, p. 1141: «El Estado no se desvanece sino en la sombra del Imperio», y según Nuevos escolios, I, p. 864: «La última idea política fue el Sacro Imperio».

${ }^{121}$ Sucesivos escolios, p. 1369. 
semifeudales»; «donde se piense que el legislador no es omnipotente, la herencia medieval subsiste»; «el terror es el régimen natural de toda sociedad sin rastros de feudalismo» ${ }^{122}$.

En cuanto al fruto histórico del feudalismo (y de su legado romano), varios escolios nos lo recuerdan utilizando siempre terminología de sentido unitario o integrador: «Europa propiamente dicha», «la auténtica infraestructura de la Europa pretérita», «la civilización de Occidente», «Occidente», «los cimientos de Occidente», «el tapiz de Occidente» ${ }^{123}$. Hay otro pasaje que va mucho más lejos aún al afirmar que «el esquema social del Medioevo es el paradigma de la estructura social de la civilización» ${ }^{124}$. De «paradigma eterno» se habla en un texto más ${ }^{125}$, y coronándolo idealmente todo, encontramos una asombrosa explicación que considera la relación entre el cristianismo y Cristo como el prototipo de la relación feudal, y concluye que «el cristianismo es un vasallaje místico» ${ }^{126}$.

Sin ningún propósito de exhaustividad cabe añadir todavía dos observaciones. Una sobre la América hispana, donde los Reyes Católicos, impulsores del Estado moderno como es de sobra sabido, impidieron el establecimiento de estructuras feudales ${ }^{127}$, y la otra para subrayar una vez más la singularidad del feudalismo frente a cualquier otro sistema político, en esta ocasión a consecuencia de la calidad de los sentimientos sobre los que se asentó ${ }^{128}$.

122 Sucesivos escolios, p. 1281; Sucesivos escolios, p. 1371, y Escolios, II, p. 510, respectivamente.

123 Por orden de cita: Escolios, I, p. 345; Escolios, I, p. 409; Escolios, I, p. 411 (y Nuevos escolios, I, p. 1008); Nuevos escolios, I, p. 947; Nuevos escolios, I, p. 969, y Nuevos escolios, II, p. 1084.

124 Nuevos escolios, II, p. 1084: «El esquema social del Medioevo es el paradigma de la estructura social de la civilización.// Complejo social de señoríos rurales y de repúblicas urbanas organizado jerárquicamente en pirámide temporal paralela a una pirámide espiritual autónoma» (énfasis nuestro).

${ }_{125}$ Escolios, II, p. 786. Vid. también Sucesivos escolios, p. 1324 (supra, nota 95).

126 Escolios, II, p. 532: «La relación entre el cristianismo y Cristo es el prototipo de la relación feudal.// Señor que da la vida por sus fieles. Vasallos fieles al señor hasta el martirio.// El cristianismo es un vasallaje místico».

${ }^{127}$ Escolios, II, p. 469: «Recelosos de la implantación de estructuras feudales en América, los Reyes Católicos, tanto como Habsburgos y Borbones, hicieron abortar todo embrión de feudalismo, logrando así que sólo tres factores tejieran la historia de este continente: la pusilanimidad del burócrata, la codicia del tendero y la anarquía del mestizo».

${ }^{128}$ Escolios, II, p. 531: «El feudalismo se fundó sobre sentimientos nobles: lealtad, protección, servicio.// Los demás sistemas políticos se fundan sobre sentimientos viles: egoísmo, codicia, envidia, cobardía». Cfr. Nuevos escolios, II, p. 1023: «No importa nuestra mediocridad si en lugar de degradarla en envidia la ennoblecemos en vasallaje». 


\section{Aristocracia}

El fenómeno nobiliario es connatural al feudalismo medieval europeo pero no finaliza con él, sino que dura mucho más allá de sus límites históricos reconocidos. Los textos sobre aristocracia y nobleza que vamos a repasar tienen detrás, ciertamente, uno u otro de estos aspectos: la conexión con el orden feudal y la continuidad más allá de él. Antes de verlos registramos un comentario que pone de manifiesto que la relación de la aristocracia con la jerarquía reside en la propia inteligencia; ésta, en efecto, es facultad «espontáneamente aristocrática» desde que se aplica a «distinguir diferencias y fijar rangos» ${ }^{129}$.

Nicolás Gómez Dávila considera que «las aristocracias son los partos normales de la historia» ${ }^{130}$, por tanto, los frutos que ésta produce cuando no se tuerce violentamente su curso normal (aunque aquí, la metáfora fisiológica empleada sugiere que el adjetivo «normal» significa algo muy parecido a «natural»). Entendemos, entonces, que de ese curso «normal» de la historia forman parte las dos condiciones que otro escolio señala como necesarias para que la aristocracia pueda nacer, a saber, «que las leyes no lo impidan y que no lo faciliten» ${ }^{131}$. Por otro lado, entre pueblo y aristocracia no hay verdadera oposición; lejos de ello, «la aristocracia auténtica es un sueño popular traicionado por las aristocracias históricas» ${ }^{132}$, «nada hay más acorde con los instintos populares que una aristocracia» y ésta «tiene que caer en extremos de estupidez para que el pueblo la derribe» ${ }^{133}$. Más aún, de «pueblo» sólo se puede hablar con exactitud allí donde existe aristocracia ${ }^{134}$.

${ }_{129}$ Escolios, II, p. 576. Cfr. Escolios, II, p. 665: «La inteligencia no conoce barreras, pero tiene peldaños»; Nuevos escolios, I, p. 930: «La inteligencia es inicuamente clasista.// Nada más deprimente que el inmenso proletariado de las bibliotecas», y Nuevos escolios, II, p. 1137: «Sólo el que enseña diferencias educa la inteligencia».

${ }_{130}$ Escolios, I, p. 294 (según este escolio, las democracias son «los abortos» de la historia»). Para A. DE Tocqueville, La democracia en América, op. cit., p. 370, nota h, las aristocracias son asociaciones naturales que frenan los abusos del poder.

${ }^{131}$ Escolios, II, p. 598.

132 Nuevos escolios, I, p. 878.

133 Escolios, II, p. 670. Cfr. A. De TocQueville, La democracia en América, op. cit., p. 964: «Una aristocracia no muere en un día, como un hombre. Su principio se destruye lentamente en el fondo de las almas antes de ser atacado en las leyes [...] una aristocracia que ha dejado escapar definitivamente de sus manos el corazón del pueblo es como un árbol muerto en sus raíces, al que los vientos derriban tanto más cuanto más alto es», y Notas, p. 77: «No es contra el feudalismo que se hizo la Revolución Francesa, sino contra su carencia».

${ }_{134}$ Cfr. Escolios, II, p. 481: «En este aburguesamiento universal, añoro menos la aristocracia muerta que el pueblo desaparecido»; Escolios, II, p. 851: «El reaccionario no conde- 
Si nos preguntamos por las características de la sociedad aristocrática (o sociedad nobiliaria; para nuestros fines podemos dar por equivalentes las dos denominaciones) ${ }^{135}$, difícilmente los textos del colombiano nos darán una respuesta suficiente. No faltan algunos que parecen decir cómo es aquel tipo de sociedad, pero su concentración en el punto de vista ético y su carácter preferentemente alusivo nos dejan in albis acerca de otros aspectos como, en particular, el contenido de la relación superior-inferior. Veamos esos pasajes. Según Notas, aristocrática es aquella sociedad «donde el poder reside en manos de quienes tienen el máximum de deberes» ${ }^{136}$; un escolio señala que «sociedad aristocrática es aquella donde el anhelo de la perfección personal es el alma de las instituciones sociales» ${ }^{137}$ y otro apunta que «sociedad noble es aquella donde obediencia y mando son comportamientos éticos, y no meras necesidades prácticas» ${ }^{138}$. Este tipo de comentarios permite seguramente inferir que la obediencia y el mando son maneras de la perfección personal, pero están muy lejos de suministrar una descripción satisfactoria de la sociedad aristocrática ${ }^{139}$. Más concreto es el contenido de otro aserto — «la clase dirigente de una sociedad agrícola es una aristocracia, la de una sociedad industrial una oligarquía»— ${ }^{140}$ que por

na la mentalidad burguesa, sino su predominio.// Lo que los reaccionarios deploramos es la absorción de la aristocracia y del pueblo por la burguesía.// So capa, alternativamente, de libertad o de igualdad»; Nuevos escolios, I, p. 886: «"Sociedad sin clases" es aquella donde no hay aristocracia, ni pueblo.// Donde sólo circula el burgués», y Nuevos escolios, I, p. 952: «El clero regular tiene aristocracia y pueblo: familia benedictina, órdenes mendicantes.// Los jesuitas son la burguesía de la Iglesia».

135 Vid., no obstante, R. J. DE EsPonA, Historia del Derecho nobiliario español. Una introducción, Santiago de Compostela, Andavira, 2015, pp. 173 y ss., que ofrece una buena explicación de la relación y las diferencias entre nobleza y aristocracia.

136 Notas, p. 308.

137 Escolios, I, p. 343. Cfr. Escolios, I, p. 218, donde se afirma que las «éticas aristocráticas», basadas en «la calidad de la persona», hacen depender la moralidad del acto «de la índole del agente».

138 Sucesivos escolios, p. 1389. Aquí se intuye cierta afinidad con la «idea de la virtud introducida en el mundo político» expuesta por A. DE TOCQUEvILLe, La democracia en América, op. cit., p. 436, que escribe lo siguiente: «El hombre que obedece a la violencia se doblega y se rebaja, pero cuando se somete al derecho de mandar que reconoce a su semejante, se alza de alguna forma por encima del mismo que le manda». Late en el fondo la idea aristotélica de la obediencia como «la única y verdadera escuela del mando» (ARISTÓTELES, Politica 3, 1277b).

139 No encontramos ayuda en Nuevos escolios, II, p. 1174: «Noble es la sociedad que no espera para disciplinarse que la disciplinen las catástrofes»; frase que sigue privilegiando el perfil ético y que, por otra parte, nos interpela acerca de la nobleza de nuestra sociedad más actual.

${ }^{140}$ Escolios, II, p. 805. De nuevo es posible notar afinidad con la distinción de A. DE 
lo menos informa del ambiente propicio a la formación de la aristocracia tal como la concibe el colombiano.

Lo más parecido a un rasgo característico es la importancia del rito y la liturgia, y de la función educativa que se les atribuye, de acuerdo con sendos escolios que, por lo demás, constatan la presencia de estos elementos en la sociedad aristocrática pero no lo explican ${ }^{141}$. Orgullo, lealtad, honor, cortesía, finura, dignidad, vasallaje: palabras todas de los comentarios relativos a la aristocracia que sirven apenas para enterarnos de algunos valores propiamente aristocráticos, pero que tampoco dicen gran cosa acerca de la relación superior-inferior.

Dada esta penuria informativa, cabe tomar la frase de Notas sobre el máximum de deberes inherente a los miembros de la nobleza, antes citada, como el polo que permite establecer una conexión más estrecha con el «Estado social» del que, debemos suponer, el orden aristocrático es a un tiempo «condición» y garantía ${ }^{142}$. En Notas también se dice que

Tocqueville, La democracia en América, op. cit., pp. 931 y s., entre la «aristocracia territorial» y la «aristocracia manufacturera».

${ }^{141}$ Escolios, I, p. 343: «A la sociedad democrática le basta, en el mejor de los casos, asegurar la convivencia.// Las sociedades aristocráticas, en cambio, levantan sobre la gleba humana un palacio de ceremonias y de ritos para educar al hombre»; Escolios, I, p. 344: «Las fiestas democráticas conmemoran motines victoriosos. La aristocracia prefería las pompas litúrgicas.// La fiesta de la Federación termina en bailes de barrio. La etiqueta imperial se prolongó en el rito galicano de una misa milanesa», y Nuevos escolios, p. 1158: «El formalismo aristocrático evita la grosería sin caer en la impostura». El «rito galicano» estuvo en uso en las iglesias de Francia más o menos entre los siglos v y IX; cabe dudar de la conformidad del comentario que lo menciona con aquel otro según el cual «la verdadera religión es monástica, ascética, autoritaria, jerárquica» (Escolios, II, p. 529).

${ }_{142}$ Ya que venimos señalando la cercanía de Gómez Dávila a Tocqueville, no está de más complementar lo que se dirá seguidamente en el texto con el retrato que hace el aristócrata francés del «estado social» al que aluden los comentarios del colombiano: «Cuando el poder real, apoyado en la aristocracia, gobernaba apaciblemente los pueblos de Europa, la sociedad gozaba en medio de sus miserias de algunos géneros de dicha que difícilmente se pueden concebir y apreciar en nuestros días.// El poder de algunos súbditos alzaba barreras insuperables contra la tiranía del príncipe y, por otra parte, los reyes, revestidos a los ojos de la multitud de un carácter casi divino, obtenían del respeto mismo que inspiraban la voluntad de no abusar de su poder.// Los nobles, situados a inmensa distancia del pueblo, se tomaban por su suerte, sin embargo, esa especie de interés benévolo y tranquilo que el pastor tiene por su rebaño y, sin ver en el pobre a su igual, velaban por su destino como por un depósito puesto en sus manos por la Providencia.// El pueblo, que no había concebido ni por asomo la idea de otro estado social que el suyo, sin imaginar poder igualarse nunca a sus jefes, recibía sus beneficios y no discutía sus derechos. Los quería cuando eran clementes y justos y se sometía sin pena ni bajeza a sus rigores, como a males inevitables enviados por la mano de Dios. Además, el uso y las costumbres habían establecido límites a la tiranía y fundado una especie de derecho en medio de la fuerza». También: «En una aristocracia el pueblo está al abrigo de los excesos del despotismo, por- 
es «privilegio» —o sea, ventaja, utilidad o prerrogativa— «de un Estado aristocrático, y de él sólo» preservar «la integridad del individuo»e impedir a la vez, por medio de la estructura que le da, la conversión de la sociedad «en una masa amorfa» ${ }^{143}$. Si se observa con atención, no se trata de dos resultados distintos, sino de las dos caras de un solo resultado. Esto quiere decir, por ejemplo, que la integridad preservada es la del individuo en general y no solamente la del aristócrata (lo obvio se puede pasar en silencio); que la estructura aludida la componen individuos de una pieza, cada uno colocado en el lugar que le corresponde por su rango, y que tal estructura no es sino el esqueleto sobre el que se sostiene la forma o la figura de una sociedad que no carece de ella ${ }^{144}$. Ahora bien, la clave de todo ello es la presencia y la acción de un grupo de privilegiados en los que reside el poder y que tienen el máximum de deberes ${ }^{145}$. Bueno será entonces dirigir la atención hacia el tipo individual del aristócrata.

Para empezar, una declaración nada extraordinaria a estas alturas si no es porque admite que la nobleza es cualidad moral que puede adornar a cualquier individuo: «Noble no es el que cree tener inferiores, sino el que sabe tener superiores» ${ }^{146}$. Son varios los escolios que contornean esta noción dilatada de la nobleza en tanto cualidad personal, considerada, por encima de todo, un ethos del individuo que no precisa de ningún apoyo externo para darse ${ }^{147}$. La idea culmina en la declaración de que

que hay siempre fuerzas organizadas dispuestas a resistir al déspota» (A. DE TocQueviLLE, La democracia en América, op. cit., pp. 128 y s., y 249).

143 Notas, p. 307. La expresión es un tanto dificultosa: la locución «Estado aristocrático» se utiliza sólo para no repetir la palabra «sociedad»; la locución adverbial «a la vez» parece fuera de sitio: «salvar, a la vez, la integridad del individuo y erigir una estructura». El tema de esta nota es idéntico al de Escolios, I, p. 284, y Nuevos escolios, I, p. 955 (vid. supra, nota 40). Según Notas, p. 309: «El gobierno aristocrático prepara al individuo a bastarse a sí mismo».

144 Síntesis sugerente en Notas, p. 310: «La civilización perfecta sería aquella que lograra unir a la noción de individuo del Renacimiento italiano, la noción de orden del Feudalismo francés».

145 Con toda seguridad, «máximum de deberes» significa los deberes más altos o de mayor trascendencia. Basada en un principio de proporcionalidad entre privilegios y obligaciones, la nobleza tiene una doble inspiración jurídico-premial y social funcional. Sobre la ratio legis de la nobleza cfr. R. J. DE EsPONA, Historia del Derecho nobiliario español..., op. cit., pp. 89 y ss.; en p. 120 este autor recuerda la definición de dignitas dada por Bártolo de Sassoferrato: «Dignitas accipit pro quadam qualitate, quae facit persona differre a plebeis, $\mathcal{E}$ iste est nobilitas secundum vulgare nostrum».

146 Nuevos escolios, II, p. 1069. Por lo demás, en cuanto inserto en la escala jerárquica, todo noble tiene, en efecto, superior o superiores.

${ }_{147}$ Escolios, I, p. 112: «La nobleza humana es obra que el tiempo a veces labra en nuestra ignominia cotidiana»; Escolios, I, p. 255: «Ser aristócrata es no creer que todo depende de la voluntad»; Escolios, I, p. 305: «Verdadero aristócrata es el que tiene vida interior. Cualquie- 
«el supremo aristócrata no es el señor feudal en su castillo, sino el monje contemplativo en su celda» ${ }^{148}$. Es cierto, no obstante, que hay algunos rasgos y actitudes que, sin merma de su condición general, se consideran distintivos del aristócrata propiamente dicho: orgullo y lealtad, honor, cortesía, finura y dignidad ${ }^{149}$. En este sentido, o sea, para cualidades y virtudes que, aun radicadas en una exigua capa de individuos, labran con eficacia la figura de la sociedad, la aristocracia supone «una posibilidad de existir» que les concede la tenencia firme del poder y la fortuna ${ }^{150}$.

Enlaza con lo anterior la afirmación de que «el aristócrata no defiende la libertad para asegurar la autonomía de su voluntad, sino la autonomía de las normas propias a la perfección personal de cada individuo» ${ }^{151}$. Se alude aquí a uno de los deberes -el más alto seguramente, o la cifra de todos ellos- que incumbe al aristócrata, a saber, la defensa de la libertad en provecho de todos. Se trata de una de esas ideas precoces de Gómez Dávila que, esbozada ya en Notas $^{152}$, se expone de forma mucho más explícita en un comentario situado bastante al principio del primer volumen de los Escolios: «Nada más noble que el aristócrata liberal —como Tocquevillepara quien la libertad de todos es el privilegio que compete defender a la clase dirigente» ${ }^{153}$. No hay duda de que aquí reside también la razón por la que se repite, en Notas y en los Escolios ${ }^{154}$, que «el amor al pueblo es vocación de aristócrata».

ra que sea su origen, su rango o su fortuna»; Escolios, II, p. 470: «Aquellos cuya gratitud por el beneficio recibido se convierte en devoción a la persona que lo otorga, en lugar de degenerar en el odio acostumbrado que todo benefactor despierta, son aristócratas.// Aun cuando caminen en harapos»; Escolios, II, p. 582: «Noble es la persona capaz de no hacer todo lo que podría», y Nuevos escolios, II, p. 1080: «La mejor prueba de nobleza está en no desear vengarse de los beneficios recibidos». En conjunto, estos comentarios no intentan definir la nobleza, sino describir, a lo sumo, algunos de sus rasgos característicos. Cfr. Escolios, I, p. 112: «Dar una definición de nobleza sería impertinente con ciertos lectores y enigmático para otros».

148 Escolios, I, p. 306.

149 Nuevos escolios, II, p. 1214; Nuevos escolios, I, pp. 903 y 904, y Sucesivos escolios, p. 1336, sobre los «modales aristocráticos». El «gesto aristocrático» se señala por la gratuidad y por su motivación en un valor auténtico (Escolios, II, p. 472); hay también «éticas aristocráticas» en las que la moralidad del acto no depende de su efecto ni de su motivación, sino «de la índole del agente» (Escolios, I, p. 218).

${ }^{150}$ Nuevos escolios, p. 1158.

151 Escolios, I, p. 344.

152 Notas, p. 309: «Los guardianes de la libertad son los aristócratas, los enemigos del césar».

${ }^{153}$ Escolios, I, p. 79. Vemos aquí el privilegio señalado como algo «que compete» a la clase dirigente, concepto muy próximo al de deber; el antecedente de este escolio se encuentra en Notas, p. 344. Para la referencia a Tocqueville vid. supra, nota 142.

${ }^{154}$ Notas, p. 308, y Escolios, I, p. 78. 
Por lo demás, ya que venimos preguntándonos por la relación superiorinferior, no es inoportuno traer a colación un escolio que distingue entre sumisión y subordinación. En el lenguaje común estos vocablos son sinónimos; sin embargo, la etimología nos enseña una diferencia que asimismo exterioriza la morfología: summitto y subordino denotan uno y otro la idea de colocar «bajo o debajo de», su diferencia está en la manera y el propósito de ese colocar; en efecto, separada la preposición sub que ambos verbos incorporan, nos quedan mitto y ordino, que significan, respectivamente, enviar, transmitir, echar, poner en general y ordenar, poner en orden, disponer en orden regular. La subordinación, por tanto, implica la colocación del inferior no sólo «bajo o debajo de», sino en aquel lugar que es el suyo dentro de un orden existente y conocido; la sumisión, en cambio, es mera y hosca sujeción. El escolio en torno al que gira esta reflexión describe, en definitiva, dos formas distintas de eso que decimos poner o colocar «bajo o debajo de». Veamos en qué términos lo hace: «La sumisión es relación entre grupos. La subordinación es relación entre personas». En una relación impersonal como es la primera, el individuo — debe entenderse el inferior«se siente» simplemente «sometido» a un «amo» indefinido, sentimiento que inevitablemente ha de resultarle incómodo y difícil de aceptar. En una relación personal como es la segunda, aquél «sólo se siente subordinado» ante un «amo personal» cuya superioridad, añadimos por nuestra cuenta, en principio entiende y reconoce. De ahí también que en la primera situación el mero «uso» baste para provocar «revoluciones», mientras que en la segunda es el «abuso» lo que produce «insurrecciones» ${ }^{155}$.

${ }^{155}$ Escolios, II, p. 693. Probablemente, la utilización de los términos revolución e insurrección tampoco es casual; el segundo procede del verbo insurgo y significa «levantamiento o alzamiento contra» (lógicamente contra el abuso del amo o del superior), pero acaso sin el alcance, que sí tiene el primero, de abolir el orden establecido; en esta línea cabe leer también algunos comentarios que contraponen rebelión y revolución, entre ellos Escolios, II, p. 765: «La revolución es progresista y busca el robustecimiento del Estado; la rebelión es reaccionaria y busca su desvanecimiento», y Escolios, II, p. 767: «La rebelión es reacción contra una condición intolerable, la revolución es técnica de un proyecto burgués». En el Código de Justiniano se recoge una ley del año 342 (Cod. Iust. 9.9.30) que puede servir para ilustrar lo que intentamos decir: «Cum vir nubit in feminam, femina viros proiectura quid cupiat? ubi sexus perdidit locum, ubi scelus est id quod non proficit scire, ubi venus mutatur in alteram formam, ubi amor quaeritur nec videtur: iubemus insurgere leges, armari iura gladio ultore, ut exquisitis poenis subdantur infames, qui sunt vel qui futuri sunt rei». Es decir, las leyes se levantan y se arma el derecho en defensa del orden o de lo que así se considera, en este caso en materia de relaciones sexuales (cfr. ubi sexus perdidit locum). «El aristócrata castiga al insurrecto; el burgués se venga de su susto», dice otro comentario (Nuevos escolios, II, p. 1218). J. M. SerRano Ruiz-CaLderón, Democracia y nibilismo..., op. cit., p. 245, señala con acierto indudable que ninguna palabra es casual en los escolios. 
Un aspecto más de la aristocracia al que queremos hacer por lo menos una alusión es el de la fortuna y la herencia, ya que ambas en estrecha relación constituyen de algún modo, subraya Gómez Dávila, la base material de la nobleza. En efecto, en opinión del colombiano, la carencia de fortuna suficiente dificulta la tenencia firme del poder que es necesario al aristócrata; por otro lado, esa fortuna suficiente coincide poco más o menos, en su concepto y en su extensión, con la hacienda -o sea, con la propiedad de bienes raíces, sobre todo rústicos-y, de forma más concreta, con lo que solemos conocer como «heredad». Por sí sola, esta palabra remite al orden de ideas propio de la sucesión. Pues bien, la importancia de la herencia se destaca en un escolio que la conceptúa como justificación de la propiedad por encima del trabajo ${ }^{156}$; hasta tal punto sería esto así que la «esencia de la propiedad» consiste, para otro escolio, en la «unión indisoluble de una familia y de una tierra» ${ }^{157}$. La existencia de propiedad concebida de esta manera y «amparada por una legislación "clasista"» parece «injusta» a muchos, pero Gómez Dávila sugiere que es la condición que permite, por lo menos a algunos, escapar «a la necesidad de vivir en postura servil» ${ }^{158}$. Esos pocos son máximamente los aristócratas, y éstos, a su vez, los individuos a quienes la nobleza y la fortuna heredadas garantizan una libertad y un poder de los que depende el amparo de los inferiores ${ }^{159}$. El curso de la historia, hace notar nuestro autor, «sirve platos poco apetecibles», a saber, «plutocracia burguesa»y «policía socialista»; más deseable le parece la «nobleza hereditaria» que antecedió a las dos, pese a las «viejas ficciones» que constituyen en buena parte su fundamento ${ }^{160}$.

${ }^{156}$ Escolios, II, p. 810: «La propiedad no es justificable porque pueda originarse en el trabajo, sino porque puede ser hereditariamente transmitida».

${ }^{157}$ Escolios, II, p. 553, texto según el cual todo lo que no sea esa unión «consiste en posesiones equívocas y desmoralizadoras». De acuerdo con Notas, p. 113: «La propiedad de los instrumentos de producción es la sola garantía de la libertad. Digamos, aun excesivamente: quien no tiene tierra, no tiene libertad».

${ }^{158}$ Escolios, II, p. 631. Cfr. Escolios, I, p. 248: «Sólo escapan a la veneración del dinero los que eligen la pobreza, o los que heredan su fortuna.// La herencia es la forma noble de la riqueza». Sobre la importancia de la riqueza para la conservación práctica de la nobleza vid. R. J. DE Espona, Historia del Derecho nobiliario español..., op. cit., pp. 70 y ss.

${ }_{159}$ Cfr. cómo se organizan los anhelos de los hombres según Notas, pp. 112 y s.: la libertad es «una aspiración subalterna, un deseo secundario» en toda situación en que las necesidades materiales de las masas permanecen sin satisfacer y sin cubrir sus deseos de seguridad; la libertad «es la pasión política de los ricos, los poderosos y los grandes». En la misma dirección vid. Nuevos escolios, II, p. 1233: «La libertad es sueño de esclavos.// El hombre libre sabe que necesita amparo, protección, ayuda».

160 Escolios, II, p. 661. 
Concluimos con dos observaciones complementarias que combinan paradoja e ironía: «La democracia es "elitista". Siempre pretende escoger, aun cuando siempre escoja mal.// Monarquía y aristocracia aceptan simplemente la casualidad genética» ${ }^{161}$; «Nuestra sociedad insiste en elegir a sus gobernantes para que el azar del nacimiento, o el capricho del monarca, no entreguen el poder, de pronto, a un hombre inteligente» ${ }^{162}$.

\section{IGUALDAD}

La democracia pretende escoger y en esto es elitista, pero su método no es el de la aristocracia; en efecto, si ésta se basa en el privilegio y en la desigualdad, incluso fortuitos, aquélla prefiere proclamarse igualitaria. La igualdad es precisamente el último concepto del que debemos ocuparnos. Los textos gomezdavilianos sobre el particular son tan numerosos que su examen se haría muy difícil sin algún tipo de clasificación previa. La que hemos adoptado, puramente funcional y discutible como cualquier otra, los divide en varios grupos que se pueden rotular así: igualdad y divinidad; igualdad y experiencia personal; igualdad y justicia; igualdad y economía; igualitarismo; consecuencias de la igualdad. Al final añadiremos una conclusión que enlaza igualdad y civilización.

Como hace el propio Gómez Dávila, al relacionar igualdad y divinidad aplicamos ambos términos al hombre en cuanto rechaza su condición de creatura. En la base de la pretensión igualitaria se encontraría, en efecto, ni más ni menos, la asunción implícita de la participación de cada hombre en la divinidad. Ahora bien, ¿qué condición divina es ésta que el hombre compartiría? No se trata, evidentemente, del Dios cristiano ni de la relación filial que tienen con él sus creaturas. Sabiéndose hijo de Dios, el cristiano se sabe también infinitamente inferior a él: el alma es inmortal, pero no divina, y la relación filial que une al hombre con el Creador al que debe su existencia destruye de raíz la hipótesis igualitaria. La supuesta divinidad del hombre - y la igualdad como corolario suyo - se deben entender más bien en el sentido de la tesis gomezdaviliana acerca de la

161 Sucesivos escolios, p. 1401; este comentario abunda en la idea de otro que ya hemos citado según el cual «el "elitismo" es tesis democrática» (vid. supra, nota 64). Sobre los conceptos de «ejemplaridad por elección» y «aristocracia natural» de los electos en los sistemas democráticos cfr. J. Gomá Lanzón, Ejemplaridad pública, op. cit., pp. 348 y s.

162 Escolios, I, p. 382. 
democracia como «religión antropoteísta» ${ }^{163}$. El postulado explícito de esta religión sostiene que «los hombres son voluntades libres, soberanas e iguales»; tácitamente eso significa que «el hombre asume al hombre como Dios» ${ }^{164}$. En consecuencia, como observa una acotación fundamental a este respecto, si los hombres se proclaman iguales no es porque se crean hijos de Dios, sino porque se consideran partícipes de esa divinidad inmanente y pervertida. Otro escolio constata que la inferencia igualitaria remonta sus orígenes al gnosticismo; según denuncia uno más, al presente inspira la democratización del cristianismo y deforma el sentido de los textos «leyendo: igual donde dicen hermano» ${ }^{165}$.

Ésta es la cima desde la que se despliega eso que alguien ha descrito atinadamente como «el pathos antiigualitario de la concepción política gomezdaviliana» ${ }^{166}$. Por otra parte, sobre la base de cuanto se ha expuesto hasta este momento, ya ha quedado bien establecido que, en presencia de elementos, términos u objetos diferentes, la igualdad no es criterio que pueda instituir un orden conveniente, sino más bien lo contrario.

La desigualdad humana es un hecho natural del que no hay nadie que no tenga experiencia ${ }^{167}$. Hasta tal punto es esto así que lo necesitado de explicación antropológica no es tanto «el hecho» de la desigualdad

${ }_{163} \mathrm{Vid}$. Textos, pp. 62 y ss. No es cometido nuestro ocuparnos de esta teoría, sobre la cual es suficiente remitir de nuevo a la reciente exposición de J. M. SerRano Ruiz-CaldeRón, Democracia y nibilismo..., op. cit., esp. pp. 216-242; G. Hoyos VÁsqueZ, «Don Nicolás Gómez Dávila, pensador en español y reaccionario auténtico», Arbor. Ciencia, Pensamiento y Cultura, núm. 184/734 (2008), pp. 1094 y ss., revisa con ojo crítico la teoría gomezdaviliana.

${ }^{164}$ Textos, pp. 62 y 65. Un primer esbozo de esta idea aparece ya en Notas, p. 450: «Todo hombre moderno es candidato al trono vacío de Dios».

${ }_{165}$ Por el orden en que han sido citados: Nuevos escolios, I, p. 938; Nuevos escolios, I, p. 1005, y Escolios, I, p. 435. En relación con el último es especialmente esclarecedor Escolios, I, p. 429: «¿Mis hermanos? Sí. ¿Mis iguales? No.// Porque los hay menores y los hay mayores». Sobre gnosticismo y divinización del hombre vid. también, entre otros lugares, Nuevos escolios, I, pp. 983, 996, 1036, 1041 y 1045, y esp. Nuevos escolios, I, p. 1047: «La divinidad del hombre no es conclusión a que el igualitario llegue, es la convicción sobre la cual se funda». Cfr. A. ABAD TORRes, «Nicolás Gómez Dávila y las raíces gnósticas de la modernidad», Ideas y Valores, núm. 142 (2010), pp. 131 y ss.

${ }^{166}$ F. GHIA, «Nicolás Gómez Dávila e la sua filosofia tragica della storia», en F. MeroI y S. Zucal (eds.), Nicolás Gómez Dávila e la crisi dell'Occidente, Pisa, ETS, 2014, p. 117.

${ }^{167}$ Escolios, I, p. 118: «Las desigualdades naturales amargarían la vida del demócrata, si la denigración no existiera»; Escolios, I, p. 236: «Nada tan mezquino como no confesar con cuántos superiores tropezamos.// La desigualdad es experiencia del alma bien nacida»; Escolios, II, p. 478: «No existe individuo que, al medirse desprevenidamente a sí mismo, no se descubra inferior a muchos, superior a pocos, igual a ninguno», y Nuevos escolios, I, p. 940: «Los que niegan la existencia de rangos no se imaginan con cuanta claridad los demás les ven el suyo». 
cuanto «la noción» de igualdad ${ }^{168}$, aunque, como acabamos de ver, sobre este particular nuestro autor dispone de una explicación convincente. Por otro lado, aun siendo natural —espontánea, no inducida por el hombre, quien, sin embargo, la puede manejar de muy distintas formas-, la desigualdad humana no es tan absoluta que impida hablar de igualdad de los hombres ni tampoco, bien que con otro sentido, de igualdad entre los hombres ${ }^{169}$ : si no de ninguna otra, al menos habrá que aceptar la existencia de la igualdad de y entre los iguales. La cuestión, por tanto, parece ser de medida y decisión, pero sería como poco engañarse pretender que hay en esto un a priori por el que deba darse ventaja a la igualdad ${ }^{170}$. «Mientras no convierten la igualdad en dogma, nos podemos tratar como iguales» ${ }^{171}$; éste es el límite que Gómez Dávila de ningún modo está dispuesto a rebasar.

Orientarse en estos temas - la proporción entre la igualdad y la desigualdad, y las múltiples decisiones que deban tomarse acerca de elloes cualquier cosa menos fácil. En el mismo centro se encuentra situada la cuestión de la justicia, concepto éste que, sin una razón evidente, tantos asumen precipitadamente como sinónimo del que estamos examinando. Y bien podría serlo, pero con la condición de haberse comprobado previamente la igualdad: sólo entonces, después de una decisión que señalara su existencia, cabría —en relación al caso y nunca con alcance general- denunciar como signo de injusticia la obstinación en el trato desigual. Ésta podría ser la igualdad de los iguales antes mencionada, una igualdad que no sólo es la única fundada, sino también la única que pesa con peso propio en el curso de la historia ${ }^{172}$. Sucede, sin embargo, que lo que comprueba de ordinario la experiencia es la desigualdad. Si justa o injusta, eso requiere también una decisión que debería dar paso,

${ }^{168}$ Escolios, I, p. 273.

169 Escolios, I, p. 220: «Llámase problema social la urgencia de hallar un equilibrio entre la evidente igualdad de los hombres y su desigualdad evidente», y Escolios, I, p. 432: «Los hombres son menos iguales de lo que dicen y más de lo que piensan». Nótese que pensar y decir cosas distintas es señal, bien de incertidumbre, bien de hipocresía.

${ }^{170}$ Escolios, I, p. 293: «Aunque realmente fuéramos iguales, la igualdad no tiene por qué ser un ideal»; Escolios, II, p. 509: «Aun cuando la desigualdad no fuera imborrable, deberíamos preferirla a la igualdad por amor a la policromía»; Escolios, II, p. 711: «Si los hombres nacieran iguales, inventarían la desigualdad para matar el tedio», y Sucesivos escolios, p. 1340: «Tan sólo la desigualdad social rescata la vida de la monotonía y el tedio».

${ }^{171}$ Escolios, II, p. 541

172 Escolios, II, p. 804: «Las luchas de clase son episodios.// El tejido de la historia es el conflicto entre iguales». Cfr. Notas, p. 77: «Entre iguales la fuerza funda el derecho, porque allí, y allí solamente, es la fuerza calidad, es decir, lo que distingue». 
una vez tomada, al alivio de la injusticia que se haya podido percibir en la desigualdad de que se trata. Ahora bien, en recetar la igualdad como remedio consistirá, la mayoría de las veces, la producción de otra injusticia, toda vez que no siendo justicia e igualdad sino raramente equivalentes, también raramente podrá ser justa la igualdad. En definitiva, «la desigualdad injusta no se cura con igualdad, sino con desigualdad justa» ${ }^{173}$.

Hasta en tres ocasiones subraya Gómez Dávila no ya la diferencia, sino la oposición entre la igualdad y la justicia: «La igualdad no es expresión empírica de la justicia, sino versión diabólica.// Soberbia que rendir homenaje afronta»; «la igualdad no es la relativización, sino la perversión de la equidad.// Sólo una ordenación jerárquica procede equitativamente con "the lion and the ox"»; «la igualdad no es la justicia, es meramente la manera de eludir la obligación de atribuir summ cuique» ${ }^{174}$. El primer comentario rechaza una opinión que se ha convertido en vulgar y, en probable relación con la crítica del autor a la religión democrática, delata su raíz en la soberbia. Las palabras inglesas del segundo proceden de una sentencia de William Blake que, entera, dice así: «One law for the lion and the ox is oppresion ${ }^{175}$. La frase no necesita ninguna aclaración; si acaso subrayar que el colombiano obtiene dos cosas de las connotaciones culturales adosadas al león y al buey más allá de la palmaria diferencia entre estos dos animales: un ejemplo muy claro de cómo la igualdad pervierte la equi$\mathrm{dad}^{176} \mathrm{y}$ un argumento de los que entran por los ojos en pro de la ordenación jerárquica. También contiene una cita el último comentario, en esta

173 Sucesivos escolios, p. 1367. En todo caso, como se señala en Sucesivos escolios, p. 1311: «Desigualdad e igualdad son tesis que conviene defender alternativamente, a contrapelo del clima social que impere».

${ }_{174}$ Nuevos escolios, I, p. 887; Nuevos escolios, II, p. 1250, y Sucesivos escolios, p. 1398.

175 W. Blake, The Marriage of Heaven and Hell, hacia 1790, 24 (Gómez Dávila tenía una edición facsímil de 1927).

176 Un ejemplo, se podría decir también, de opresión so capa de igualdad si no incluso causada por ella: tras alcanzar la independencia, el 4 de marzo de 1819 se promulga en Chile un Bando Supremo que otorga la ciudadanía a los indígenas; en él, después de recordar que bajo las Leyes de Indias los indígenas habían vivido «siempre en la clase de menores bajo la tutela de un funcionario titulado Protector General de Naturales», se dispone que «para lo sucesivo deben ser llamados ciudadanos chilenos, y libres como los demás habitantes del Estado con quienes tendrán igual voz y representación», así como también que quedan «libres desde esta fecha de la contribución de tributos como consecuencia de su igualdad con todo ciudadano». La Ley de 4 de diciembre de 1866, que dispone la fundación de poblaciones en el territorio de indígenas y da normas para la enajenación de éstos (sic), en su art. 8 restablece por lo menos parcialmente la función y la figura del Protector de Indígenas. Vid. M. Valenzuela Reyes y S. Oliva Fuentealba (ed. e intr.), Recopilación de legislación del Estado chileno para los pueblos indígenas, 1813-2006, Santiago de Chile, Librotecnia, 2007, pp. 17 y s., y 32 y ss. 
ocasión del Digesto de Justiniano o, si se quiere, a través de él, del jurista Domicio Ulpiano. En efecto, las palabras suum cuique forman parte de la conocidísima definición iustitia est constans et perpetua voluntas ius suum cuique tribuendi de Digesto, 1.1.10 pr. (Ulp. 1 reg.), enunciado recogido también en las Instituciones imperiales (1.1. pr., con sustitución de tribuendi por tribuere) y al que Gómez Dávila alude en otro escolio y en su ensayo De iure ${ }^{177}$. La afirmación de que la igualdad es pretexto que elude la determinación de «lo suyo de cada cual» consuena con una porción de escolios que critican el relativismo y mencionan la tensión ordenar/excluir ${ }^{178}$. En último análisis, ese aserto se da la mano con la idea ya mencionada de que, desde un punto de vista general, no hay más realización auténtica de la justicia que la «desigualdad justa». De ahí la injusticia de quienquiera que trata como iguales a sus superiores ${ }^{179} \mathrm{y}$ de ahí también la prevención contra la tan publicitada igualdad de oportunidades, cuyo resultado, ya que no su finalidad, retrata el colombiano de forma que lo hace perfectamente indeseable ${ }^{180}$.

En lo que atañe a igualdad y economía, los comentarios gomezdavilianos son quizá menos contundentes, aunque pecaríamos de ingenuidad si intentáramos separarlos del conjunto al que pertenecen y, en particular, de los que se acaban de ver sobre la justicia. Dicho lo cual, parece que la desigualdad meramente económica no preocupa demasiado a nuestro autor, sin duda porque considera que la dimensión económica se distingue por una contingencia que acota su influencia en la disposición

177 Escolios, II, p. 555: «Por justicia social se entiende dar a cada cual lo que no es suyo.// Alienum cuique tribuere». N. GÓmEz DÁvILA, «De iure», op. cit., p. 69 (en las pp. 77 y ss. de este denso trabajo desarrolla el autor su concepción de la justicia y de la relación que pueda tener ésta con la igualdad). Sobre el tema vid. F. Cuena Boy, «Nicolás Gómez Dávila, la historia...», op. cit., pp. 20 y ss., y L. GAROFALO, «Roma e i suoi giuristi nel pensiero...», op. cit., pp. 11, 28. Por supuesto, la Compilación de Justiniano (el Corpus Iuris Civilis) no faltaba en la biblioteca gomezdaviliana.

${ }^{178}$ Escolios, I, p. 165; Nuevos escolios, I, p. 1051; Nuevos escolios, II, p. 1138, y Nuevos escolios, II, p. 1229. Cfr. Escolios, II, p. 600: «El que no sabe dar a cada cual lo suyo resuelve dar a todos lo mismo».

${ }^{179}$ Escolios, I, p. 276. La misma idea en CICERÓN, De rep., 1.53: «Eamque quae appellatur aequibilitas iniquissima est: cum enim par babetur bonos summis et infimis, qui sint in omni populo necesse est, ipsa aequitas iniquissima est; quid in iis civitatibus quae ab optimis reguntur accidere non potest».

${ }_{180}$ Nuevos escolios, II, p. 1131: «"Igualdad de oportunidades" no significa posibilidad para todos de ser decentes, sino derecho de todos a no serlo», y Sucesivos escolios, p. 1292: «El que reclama igualdad de oportunidades acaba exigiendo que se penalice al bien dotado». Alguien podría pensar que este último dardo acierta en el centro de la diana de un sistema educativo como el español. 
y el funcionamiento del tipo de orden preferido por él ${ }^{181}$. Adviértase, no obstante, que la observación que acabamos de hacer deja fuera las consideraciones más arriba reseñadas en torno a la base material necesaria a la nobleza, compuesta de fortuna y herencia ${ }^{182}$. Con esta salvedad, para Gómez Dávila la noción de igualdad económica plantea una cuestión de orden técnico cuyo desbordamiento supone una confusión de planos que amenaza de forma inaceptable la existencia de jerarquías ${ }^{183}$. Por lo demás, en su opinión, la actual hipertrofia de todo lo económico es «fenómeno moral» alentado por la «codicia igualitaria» que pone de manifiesto el imparable avance de dicho desbordamiento ${ }^{184}$. Y de algún modo hay que darle la razón en vista de que hoy, en efecto, en contra de casi todo lo que en vano se proclama, la observación menos atenta constata una tendencia largamente difundida a contender toda superioridad que no tenga su estribo en la «desigualdad meramente económica». Bajo esta luz se desvanece la sorpresa inicial que pudiera causar la petición de prueba de la desigualdad que se desliza en Notas: «¿Los hombres quieren la desigualdad? Bien, que prueben que son desiguales». Basta conectar esta frase con el párrafo que la precede y con los que la siguen para darse cuenta de que Gómez Dávila no acepta que la sustancia de la desigualdad pueda limitarse a lo económico ${ }^{185}$.

Aunque defiende la desigualdad, Gómez Dávila parece dirigir su antipatía menos hacia la igualdad que contra el igualitarismo ${ }^{186}$; es decir,

${ }^{181}$ Cfr. Escolios, I, p. 162: «No reprobamos el capitalismo porque fomente la desigualdad, sino porque favorece el ascenso de tipos humanos inferiores», y Escolios, II, p. 604: «La desigualdad meramente económica no dura.// Ni merece durar». Cfr. Nuevos escolios, II, p. 1181: «Los partidarios de la desigualdad debemos aplaudir la decapitación de todo beneficiario indigno».

${ }^{182}$ Cfr. Escolios, II, p. 492: «No es la riqueza lo que escandaliza al pobre, sino el enriquecimiento», y en la misma página: «El pueblo se ha burlado siempre de los nuevos ricos $\mathrm{y}$, aunque las confisque, respeta las fortunas rancias».

${ }^{183}$ Nuevos escolios, II, p. 1083: «La noción de igualdad económica plantea una cuestión puramente técnica que conviene resolver examinando las consecuencias universales de su realización.// En cambio, la noción de igualdad que niega la existencia de jerarquías debe ser lisa y llanamente rechazada».

184 Nuevos escolios, II, p. 1143: «La inflación económica de este final de siglo es fenómeno moral. Resultado, y a la vez castigo, de la codicia igualitaria».

185 Todo en Notas, p. 264. Cfr. Sucesivos escolios, p. 1339: «La prosperidad económica de un individuo no desmoraliza la sociedad mientras no conlleve necesariamente su ascenso social».

186 Vid. Nuevos escolios, II, p. 1210: «Sólo dos de los ejemplos favoritos de la propaganda democrática han logrado conmoverme: el "igualitarismo" de Esparta y el "liberalismo" de la reacción senatorial contra César». La prosa de César es ejemplo de voz aristocrática — «dura, sencilla, lúcida»— en Escolios, II, p. 842. 
contra la aspiración desenfrenada que se plantea la igualdad como objeto y como fin en sí, ya sea apoyándose en un determinado sustrato ideológico, ya como actitud meramente instintiva y reacia por principio a la reflexión. Al margen de esta diferencia, la naturaleza del fenómeno es siempre la misma: el igualitarismo o pasión igualitaria no es defecto nacido de una envidia que se haya podido alimentar de la experiencia, sino vicio específico del alma consistente en una «congénita resistencia a soportar una superioridad cualquiera» ${ }^{187}$. «Perversión del sentido crítico» y «atrofia de la facultad de distinguir» son su más exacta diagnosis ${ }^{188}$. Los síntomas que delatan al individuo igualitario serían, entre otros, la mirada hostil o recelosa a los objetos del museo ${ }^{189}$, la repulsa de la caridad con base en el prejuicio ${ }^{190}$, la grosería y el desdén como instrumentos de autoafirmación ${ }^{191}$ y la familiaridad sistemática que oculta un juicio de sí opuesto a la igualdad ${ }^{192}$. Irónicamente, Gómez Dávila añade el rasgo de la pequeñez habitual de los incondicionales del igualitarismo ${ }^{193}$, con lo que utiliza un atributo meramente físico para sugerir una valoración moral. Su descripción del ethos igualitario se corona con dos juicios severísimos: «El que es partidario de la igualdad sin ser envidioso, sólo puede serlo porque es bobo»y «hay algo definitivamente vil en el que no admite sino iguales, en el que no se busca afanosamente superiores» ${ }^{194}$.

El igualitario, de todos modos, necesita fuerzas colosales para perseverar en su postura, puesta a prueba por los hechos con los que su pasión choca a cada paso. Así, por ejemplo, «se exaspera viendo que la instrucción

187 Sucesivos escolios, p. 1402. Cfr. Escolios, II, p. 499: «En las democracias, donde el igualitarismo impide que la admiración sane la herida que la superioridad ajena saja en nuestras almas, la envidia prolifera.// La envidia es el innoble sustituto democrático del homenaje».

188 Escolios, I, p. 240. Cfr. Escolios, I, p. 426: «Las ideas igualitarias distorsionan nuestra percepción de lo contemporáneo y truncan además nuestra visión de la historia».

189 Escolios, II, p. 667.

190 Escolios, II, p. 818: «La caridad, para el igualitario, es un resabio feudal».

191 Escolios, II, p. 758: «El igualitario considera que la cortesía es confesión de inferioridad.// Entre igualitarios la grosería marca el rango»; Nuevos escolios, I, p. 885: «El desdén suele ser igualitarismo larvado: denegación de autonomía a virtudes subalternas»; Nuevos escolios, I, p. 912: «El que irrespeta para demostrar su igualdad patentiza su inferioridad», y Nuevos escolios, I, p. 1022: «Sólo es respetuoso el que subraya con vigor las diferencias».

${ }^{192}$ Nuevos escolios, I, p. 876: «La familiaridad sistemática es hipocresía de igualitario que se juzga a sí mismo inferior, o superior, pero no igual».

${ }_{193}$ Escolios, II, p. 606: «Los partidarios de la sociedad igualitaria suelen ser siempre chiquitos».

${ }_{194}$ Escolios, II, p. 594, y Sucesivos escolios, p. 1280. Cfr. Nuevos escolios, II, p. 1171: «Ni en materia de placeres debemos aceptar estimación igualitaria.// El placer del cerdo es placer de cerdo». 
obligatoria sólo borra la desigualdad ficticia para agravar la congénita» ${ }^{195}$, y ahí encuentra sin ninguna duda su razón para exigir la penalización del bien dotado ${ }^{196}$. Lo anterior viene a dibujar el paradigma al que se atiene la extensión coactiva del proyecto igualitario con los instrumentos de la ley y la administración; fenómeno bien conocido a cuya luz la perturbadora afirmación de que «el igualitarismo no es homenaje a los derechos de quienes nos siguen, sino intolerancia de los derechos de quienes nos preceden ${ }^{197}$ resulta perfectamente irreprochable. Como es evidente, asoma también por aquí la difícil relación que la porfía igualitaria mantiene con la libertad, toda vez que la igualdad prohíbe el derecho a la diferencia en que la libertad consiste ${ }^{198}$. He ahí una dialéctica incómoda para el igualitario, incapaz no sólo de desentenderse de ella, sino, sobre todo, de domeñarla, pues, en efecto, por más que se insista en predicar lo contrario, «donde la igualdad deja que la libertad entre, la desigualdad se desliza» ${ }^{199}$.

$\mathrm{Y}$ aun con todo, ¿cómo suelen discurrir las cosas entre los propios adeptos de la idea? Dos comentarios nos lo explican ${ }^{200}$ : «aun entre igualitarios fanáticos el más breve encuentro restablece las desigualdades humanas» $\mathrm{y}$ «entre igualitarios, trátese de individuos o de naciones, el inferior hasta logra que lo inviten, pero nunca que lo escuchen». O sea, la sensibilidad igualitaria es así de quebradiza y quizá su portador no merece el sentimiento al que otro pasaje nos invita: «Compadezcamos al igualitario.// Qué infortunio ignorar que hay rangos y rangos por encima de nuestra mediocridad» ${ }^{201}$.

Apuntamos para ir terminando algunas consecuencias de esa igualdad igualitaria tan distinta de la sutil igualdad de los iguales. En el plano social, la principal de todas ellas es la atomización y el aislamiento a los que nos hemos referido ya en más de una ocasión. A fin de no repetirnos en exceso la detallamos ahora mediante nuevos comentarios que ponen de relieve su significado. Para empezar, la sociedad igualitaria se compara a una estepa

${ }^{195}$ Escolios, II, p. 779.

196 Sucesivos escolios, p. 1292; el texto supra, nota 180.

197 Escolios, I, p. 356. Cfr. la cruda afirmación de Notas, p. 298: «No es la libertad lo que el esclavo anhela, sino la esclavitud de su amo».

198 Nuevos escolios, I, p. 984: «La libertad es derecho a ser diferente; la igualdad es prohibición de serlo». En Notas, p. 69, se afirma que la coexistencia de la libertad y la igualdad es imposible «porque, patentemente, los hombres no amamos la libertad, sino solamente ser libres».

199 Sucesivos escolios, p. 1302.

${ }^{200}$ Escolios, I, p. 204, y Escolios, II, p. 701.

201 Escolios, II, p. 598. 
rasa que no ofrece resguardo al individuo ${ }^{202}$. La individualidad se difumina, en efecto, en ese paisaje desolado donde los hombres, cada vez más parecidos entre sí, dimiten de su subjetividad y se vuelven componentes comunes de una especie de producción en serie, a la vez que la competencia de todos por lo mismo los sumerge en un estado de mutua hostilidad ${ }^{203}$. Sin necesidad de evocar las experiencias más crueles y mortíferas de un pasado todavía reciente, un conocedor superficial de la ingeniería social de nuestro tiempo no debería sorprenderse demasiado cuando Gómez Dávila asegura que «la igualdad es la condición psicológica de las degollinas científicas y frías» ${ }^{204}$ (degollinas laborales, financieras, culturales y educativas, etc.). Todo esto no es de ningún modo figuración encendida de reaccionario. A conclusión muy parecida se llega aplicando la lente sobre la racionalidad burocrática moderna ${ }^{205}$, cuyo avance en los últimos doscientos años largos ha conducido al «apogeo del subjetivismo» en «la forma de la despersonalización»: lo subjetivo y lo típico, en otro tiempo «ingredientes inseparables del prototipo ejemplar, personal y normativo a la vez», se encuentran hoy definitivamente divorciados, de tal forma que, como muestran el romanticismo literario y la codificación jurídica, lo subjetivo ha llegado a ser atípico y lo típico, despersonalizado ${ }^{206}$. El control de la masa - esa misma masa de la que habla un buen puñado de textos gomezdavilianos— ${ }^{207}$ y su administración por el Estado así lo han exigido, y aunque cada cual puede pensar de esto lo que quiera, lo que sí cabe pedir es, por lo menos, que revise de vez en cuando sus ideas al respecto.

${ }^{202}$ Escolios, II, p. 715: «En la estepa rasa el individuo no halla abrigo contra la inclemencia de la naturaleza, ni en la sociedad igualitaria contra la inclemencia del hombre».

${ }^{203}$ Escolios, II, p. 827: «Los individuos, en la sociedad moderna, son cada día más parecidos los unos a los otros y cada día más ajenos entre sí.// Mónadas idénticas que se enfrentan con individualismo feroz».

${ }^{204}$ Escolios, I, p. 387: «Los hombres, mientras más iguales se sientan, más fácilmente toleran que los traten como piezas intercambiables, sustituibles y superfluas.// La igualdad es la condición psicológica previa de las degollinas científicas y frías».

${ }^{205}$ Lo que sigue resume un análisis de J. Gomá Lanzón, Ejemplaridad pública, op. cit., pp. 296 y s.

${ }^{206}$ No es difícil reconocer la consonancia con Nuevos escolios, I, p. 1022: «La ética se convierte en norma jurídica donde la impersonalizan. Donde la personalizan la ética se convierte en preferencia.// La ética debe ser personalización de lo impersonal».

207 Notas, p. 307; Escolios, I, p. 387; Escolios, II, p. 618; Escolios, II, p. 827; Nuevos escolios, I, p. 955, y Sucesivos escolios, p. 1280. Las repetidas referencias al «hormiguero social» por parte de N. Berdiaev, El espíritu de Dostoyevski, Granada, Nuevo Inicio, 2008, pp. 85, $87,105,155,208,213,214$ y 218 , son vehículo de un pensamiento no muy diferente del de Gómez Dávila acerca de las consecuencias del igualitarismo (y la libertad ilimitada) sobre el que venimos discurriendo. 
Consecuencia del igualitarismo dominante es, asimismo, el decaimiento espiritual de la sociedad, que alcanza su expresión más visible y masiva en la difusión generalizada de las «virtudes cursis» ${ }^{208}$. Mucho se podría escribir sobre este tema pero no merece la pena: la empalagosa apelación a la «solidaridad» en relación con causas de cualquier tipo sobre la base de «convicciones» nebulosas y superficiales, y, en el fondo, con la despreocupación surtida por la ignorancia del significado original del lema empleado como banderín de enganche ${ }^{209}$, todo esto se retrata por sí solo. La estólida figura del buenista (Do-gooder, se dice en inglés) forma parte del espectáculo de la sociedad contemporánea. Como aspecto de la decadencia espiritual se puede catalogar también la asfixia de la imaginación causada por la supresión del oropel ${ }^{210}$, o sea, de aquel formalismo, pompa o ceremonial de que se alimentaba dicha facultad en la vieja sociedad jerárquica ${ }^{211}$.

Lo que, en cambio, no ha suprimido el igualitarismo es la «desigualdad meramente económica», como la llama Gómez Dávila, sino que la ha conservado o ha permitido su conservación hasta el punto de que la riqueza se ve consagrada hoy como único cimiento de la superioridad. Además, dado que «los ricos no son inofensivos sino donde una aristocracia los desdeña», el ocaso de la nobleza en la sociedad igualitaria ha supuesto la eliminación no de los ricos, sino sólo de los ricos decentes ${ }^{212}$; de la posibilidad, cabría parafrasear, de ser rico y decente, de ser rico decentemente.

${ }^{208}$ Escolios, I, p. 316: «En la sociedad igualitaria no caben ni los magnánimos ni los humildes, sólo hay campo para las virtudes cursis».

${ }^{209}$ Ese origen se encuentra en la locución latina in solidum, empleada en el lenguaje jurídico con el significado de «por el total»; así, para mantenernos en el plano del conocimiento común, no especializado, la obligación solidaria se define en el DRAE como aquella «que permite a cada uno de los acreedores reclamar por sí la totalidad del crédito, o que obliga a cada uno de los deudores a satisfacer la deuda entera, sin perjuicio del posterior abono o resarcimiento que el cobro o el plazo determinen entre el que lo realiza y sus cointeresados»; dicho de una persona, solidario es quien «contrae una obligación solidaria». Sólo el olvido de este origen ha podido conducir a la idea hoy usual de solidaridad como «adhesión circunstancial a la causa o a la empresa de otros». Se refiere por extenso a esta cuestión G. Bueno, Zapatero y el pensamiento Alicia. Un presidente en el país de las maravillas, Madrid, Temas de Hoy, 2006, pp. 174 y ss., y 189 y ss.; del máximo interés es la crítica a que se somete la idea moderna de solidaridad en pp. 193 y ss.

${ }^{210}$ Escolios, II, p. 560: «Las sociedades igualitarias estrangulan la imaginación, para ni siquiera satisfacer la envidia», y Escolios, II, p. 631: «La sociedad igualitaria deja a la imaginación sin pasto, al suprimir el oropel». Cfr. Notas, p. 429: «La vieja sociedad estaba organizada para permitir y favorecer lo excelente, la nueva sociedad para colaborar a la producción de lo mediocre».

211 Vid. supra, nota 141.

${ }^{212}$ Escolios, II, p. 671, y Nuevos escolios, I, p. 985. 


\section{Conclusión mínima sobre la igualdad}

Al final (no tanto del tema, sino de lo que escribe sobre él), Nicolás Gómez Dávila es menos severo de lo que podría sugerir la lectura en bloque de sus comentarios. Más arriba hemos indicado que la igualdad es para él problema de medida y decisión, y ahora, en el momento de rematar este trabajo, encontramos dos últimos escolios que parecen darnos la razón. Ambos mencionan la «sociedad civilizada»: uno subrayando la necesidad de que en ella «igualdad y desigualdad permanentemente dialoguen» como lo hicieron en la vieja sociedad cristiana ${ }^{213}$, y el otro apuntando que «el anhelo secreto de toda sociedad civilizada no es el de abolir la desigualdad, sino el de educarla» ${ }^{214}$.

Educar la desigualdad: empeño magnífico a todas luces y mucho más beneficioso que cualquier insistencia en la alucinación igualitaria.

213 Sucesivos escolios, p. 1326: «Una sociedad civilizada necesita que en ella, como en la vieja sociedad cristiana, igualdad y desigualdad permanentemente dialoguen».

214 Sucesivos escolios, p. 1377. 